\title{
WestVirginiaUniversity
}

THE RESEARCH REPOSITORY @ WVU

Graduate Theses, Dissertations, and Problem Reports

2005

\section{Three essays on pricing and risk management in electricity markets}

Serhiy Kotsan

West Virginia University

Follow this and additional works at: https://researchrepository.wvu.edu/etd

\section{Recommended Citation}

Kotsan, Serhiy, "Three essays on pricing and risk management in electricity markets" (2005). Graduate Theses, Dissertations, and Problem Reports. 2236.

https://researchrepository.wvu.edu/etd/2236

This Dissertation is protected by copyright and/or related rights. It has been brought to you by the The Research Repository @ WVU with permission from the rights-holder(s). You are free to use this Dissertation in any way that is permitted by the copyright and related rights legislation that applies to your use. For other uses you must obtain permission from the rights-holder(s) directly, unless additional rights are indicated by a Creative Commons license in the record and/ or on the work itself. This Dissertation has been accepted for inclusion in WVU Graduate Theses, Dissertations, and Problem Reports collection by an authorized administrator of The Research Repository @ WVU.

For more information, please contact researchrepository@mail.wvu.edu. 


\title{
Three Essays on Pricing and Risk Management in Electricity Markets
}

\author{
Serhiy Kotsan
}

Dissertation submitted to the College of Business and Economics at West Virginia University in partial fulfillment of the requirements for the degree of

\author{
Doctor of Philosophy \\ in \\ Economics \\ Stratford Douglas, Ph.D, Chair \\ Alexei Egorov, Ph.D. \\ Tim Phipps, Ph.D. \\ Santiago Pinto, Ph.D. \\ Hyungna Oh, Ph.D. \\ Department of Economics
}

Morgantown, West Virginia

2005

Keywords: OPF, LMP, Nash Equilibrium, Reactive Power, Portfolio

(c) 2005 Serhiy Kotsan 


\section{Abstract}

Three Essays on Pricing and Risk Management in Electricity Markets

Serhiy Kotsan

A set of three papers forms this dissertation. In the first paper I analyze an electricity market that does not clear. The system operator satisfies fixed demand at a fixed price, and attempts to minimize "cost" as indicated by independent generators' supply bids. No equilibrium exists in this situation, and the operator lacks information sufficient to minimize actual cost. As a remedy, we propose a simple efficient tax mechanism. With the tax, Nash equilibrium bids still diverge from marginal cost but nonetheless provide sufficient information to minimize actual cost, regardless of the tax rate or number of generators.

The second paper examines a price mechanism with one price assigned for each level of bundled real and reactive power. Equilibrium allocation under this pricing approach raises system efficiency via better allocation of the reactive power reserves, neglected in the traditional pricing approach. Pricing reactive power should be considered in the bundle with real power since its cost is highly dependent on real power output. The efficiency of pricing approach is shown in the general case, and tested on the 30-bus IEEE network with piecewise linear cost functions of the generators.

Finally the third paper addresses the problem of optimal investment in generation based on mean-variance portfolio analysis. It is assumed the investor can freely create a portfolio of shares in generation located on buses of the electrical network. Investors are risk averse, and seek to minimize the variance of the weighted average Locational Marginal Price (LMP) in their portfolio, and to maximize its expected value. I conduct simulations using a standard IEEE 68-bus network that resembles the New York - New England system and calculate LMPs in accordance with the PJM methodology for a fully optimal AC power flow solution. 
Results indicate that the network topology is a crucial determinant of the investment decision as line congestion makes it difficult to deliver power to certain nodes at system peak load. Determining those nodes is an important task for an investor in generation as well as the transmission system operator. 


\section{Table of Contents}

2 Efficient Taxes for Cost Revelation in a Price and Quantity Constrained Electric Power Market.

2.1 Introduction . . . . . . . . . . . . . . . . . 8

2.2 The Model . . . . . . . . . . . . . . . . . . . . . . 11

2.3 Strategic Bidding and Market Instability . . . . . . . . . . . . . 13

2.4 Taxes . . . . . . . . . . . . . . . . . . . . 16

2.5 Reaching Cost Minimizing Equilibrium . . . . . . . . . . . . . . . . 19

2.6 Examples of Cost functions for two generators . . . . . . . . . . . . . . 22

2.7 Conclusions . . . . . . . . . . . . . . . . . . . . . . . . 27

3 Efficient pricing of a bundled product of both real and reactive power 30

3.1 Introduction . . . . . . . . . . . . . . . . . . . . 31

3.2 Power Network Model . . . . . . . . . . . . . . . . . . . . . . . . 33

3.3 Costs of Reactive Power . . . . . . . . . . . . . . . . . . . . 35

3.4 Microeconomic Foundations of the Bundled Pricing . . . . . . . . . . . . . . 39

3.5 Numerical simulations of bundled pricing on 30-bus IEEE test network . . . 43

3.6 Conclusions . . . . . . . . . . . . . . . . . . . . . . . 46 
4 Mean-Variance Portfolio Analysis of the Locational Value of Generation $\begin{array}{ll}\text { Assets } & 47\end{array}$

4.1 Introduction . . . . . . . . . . . . . . . . . . . . . . . . . 48

4.2 Simulation methodology . . . . . . . . . . . . . . . . . 50

4.3 Simulation Results . . . . . . . . . . . . . . . . . . . . . 54

4.4 Adding generators . . . . . . . . . . . . . . . . . . 55

4.5 Optimal Investment Strategy _ . . . . . . . . . . . . . . . . . . . 56

4.6 Conclusion . . . . . . . . . . . . . . . . . . . . . . . . 59

5 Policy Conclusions and Paths for Further Research 62

5.1 References ............................ 64

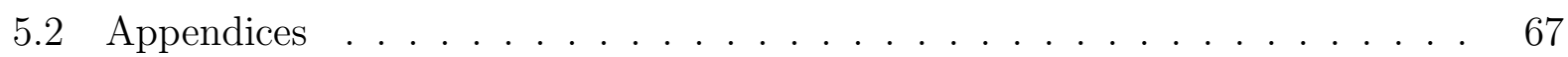




\section{Chapter 1}

\section{Introduction}

The dissertation "Three Essays on Pricing and Risk Management in Electricity Markets" is a set of three essays that apply economic theory to the power industry. The first chapter provides a brief introduction to the study of electricity markets and attempts to place the dissertation in the larger context of recent changes in the electricity market.

Chapter 2 examines strategic pricing games of generators in a stylized real-time electricity market in which price and quantities are fixed. A simple tax on generation is proposed to stabilize the market and create incentives compatible with economic efficiency.

Chapter 3 presents and simulates a locational marginal cost pricing (LMP) mechanism that accounts for both real and reactive power. In contrast to the traditional LMP approach, in which real and reactive power are priced on separate markets, the "bundled" approach links the two markets to allow more efficient distribution of reactive power resources and an autonomous competitive market mechanism for reactive power.

Chapter 4 applies a portfolio analysis approach to formulate optimal trading and generation investment strategies for a power market that employs LMPs or other locational pricing 
mechanisms. Under certain conditions, suppliers can invest in new generation that reduces the system's total production costs yet an increase in the overall price level for electricity. Chapter 5 presents a short summary of the paper contribution together with suggestions for future research.

\section{Chapter 1. Introduction}

A little more than decade ago, electric power generation, transmission and distribution were controlled by monopoly utility companies with specific service areas and customers. In 1992, Congress passed the Energy Policy Act, which defines a class of Exempt Wholesale Generators that can compete with each other for customers, and granted the FERC the right to order access to transmission lines. It opened up the possibility that tight regulation of vertically integrated monopolies might be replaced with light regulation of specialized firms and supervision of competitive markets (Wilson 2002). The potential benefits of moving to competition in wholesale electricity generation markets appeared promising, as markets can be expected to yield more efficient use of existing assets in the short run and, more importantly, the development of more efficient and reliable technology in the future. Unfortunately, this "restructuring" of the industry created some major problems, including:

- Exercise of market power via withholding production capacity;

- Lack of demand response to price change;

- Continuing regulation that sometimes ignores economics principles and creates political compromises that are not economically sustainable.

The extremely high electricity prices in California in 2001, or in the New-York blackout in 2003 provide empirical evidence for those problems. The process of establishing wholesale electricity markets is still evolving. 
In chapters two through four of my dissertation I examine three problems of electricity market implementation and suggest policies to address them. The following pages summarize each of these chapters in turn.

\section{Chapter 2. Efficient Taxation in a Price and Quantity Constrained Electric Power Market}

In this chapter of the dissertation I consider a stylized electricity market where market price and quantity are fixed. This situation may arise routinely in a market-based system during periods of peak demand or other system stress and when regulatory constraints such as price caps are in effect. The element of fixed price and quantity makes this paper different from market power literature such as Borenstein (2000) and Willems (2002).

In this scenario, a cost-minimizing system operator must satisfy an exogenously determined electricity load at a fixed price, knowing only the generators' bids, rather than their costs. The generators are assumed to know their own costs, each others' bids, and the system operator's dispatch algorithm. As in the supply function equilibrium (SFE) literature, e.g., Green and Newbery (1992), generators bid strategically. That is, the profit maximizing generators implement bidding strategies that cause their bids to depart from their true costs in order to manipulate their market share. This exercise of market power raises both equity and efficiency concerns.

I find that no Nash equilibrium exists for such a market, and that generators' bids will diverge widely from actual marginal costs, making it impossible for the system operator to minimize cost. As a remedy I propose a simple tariff mechanism that changes generators' incentives so that they voluntarily make bids that provide the system operator with enough information to determine the set of market shares that minimize the total cost of production. Although the bids diverge from true marginal cost, the outcome is fully efficient for any number of 
generators greater than one. That is, by using the tax mechanism the system operator is able to find the optimal dispatch, the same as it would if it knew each generator's actual marginal costs.

\section{Chapter 3. Efficient pricing of a bundled product of both real and reactive power}

This chapter extends the market mechanism for reactive power first laid out in "Market in Real Electric Networks Require Reactive Prices" by William Hogan (1993). In my paper I examine the benefits of pricing a bundle of real and reactive power and compared it with the traditional Locational Marginal Price where only real power is priced (PJM 2005). Reactive power can be produced by generators as a joint product together with real power, and is used to control the voltage level and network congestion in an Alternating Current (AC) system. Most economists modeling electrical networks (e.g., Hobbs 1996) neglect reactive power completely, and employ a simpler DC approximation approach to simulating power systems. Baldick and Kahn (1993) found reactive power is a cheap constraint that should not be priced.

When reactive power is produced by fast responding equipment such as Synchronous condensers it consumes approximately 3-5\% of the real power costs (FERC 2005). Reactive power does not travel over long distances at high line loadings due to significant losses on the wires. Thus, reactive power usually must be procured from suppliers near where it is needed. This factor narrows down procurement of the reactive power to the suppliers that are geographically close. With no compensation mechanism generators have no incentives to provide additional reactive power capability.

The mechanism in Chapter 3 provides two related prices for this bundle of real and reactive power output. Bundled pricing encourages efficient production of reactive power from 
existing infrastructure, taking into account the opportunity costs of competing uses of resources. The efficiency of the pricing approach is shown in the general case and tested on a 30-bus IEEE network with piecewise linear cost functions of the generators. The simulated optimal power flow solution under the bundled pricing approach is obtained and compared with the results of traditional mechanism where only real power is priced. Findings showed overall efficiency gain for the system. Generators located close to the load will benefit from the bundled pricing at most. At the same time generators that "specialize" in the real power might not be affected at all.

Proper price signals will encourage efficient and reliable investment in infrastructure needed to produce reactive power and maintain the reliability of the transmission system.

\section{Chapter 4. Mean-Variance Portfolio Analysis of the Locational Value of Generation Assets}

In this chapter I employ the mean-variance portfolio theory framework first developed by Harry Markowitz (1962) to the problem of placement of future investment in generation. The typical investor is assumed to be risk averse, and seeks a high expected locational marginal price and with the least possible vairance or risk. That is, the investor's problem is to plan the location of future generators so as to maximize the expected LMP for the given level of risk. In the electricity market literature, a similar methodology was applied by Denton (2003) to estimate determine intermediate term market risk (from one month to a year). To determine the optimal portfolio of investment on the grid, I perform simulations using a standard 68-bus IEEE system that resembles the New York New-England power network, and use PJM methodology (PJM 2005) to determine LMPs at each bus as the load increases. This method allows me to determine the set of buses that provides the highest expected LMP for given level of risk. 
On the other hand, a large scale generator added to a congested network will reduce congestion and expected prices. Therefore, in the next stage I find an ex-ante optimal portfolio by estimating the mean-variance frontier after an average generator was added to the network. Interestingly, I found that adding a generator can shift the efficient frontier either upward and downwards. A downward shift of the efficient frontier implies that by adding a generation expected prices decrease through releasing network congestion. An upward shift of the efficient frontier implies that production costs occur simultaneously with increase in expected prices. In the paper I presented a simple example showing that it is possible to happen when the marginal generators determining nodal prices are shifted upwards.

When certain lines of the network are congested, generators can manipulate nodal prices. This implies that both generation capacity and network topology play an important role in determining optimal investment strategy. Although the existing locational price mechanism may stimulate competition among generators on the spot market, it may also be misused by investors with the purpose of raising electricity prices.

\section{Chapter 5. Summary and Conclusion}

The concluding chapter of the dissertation will summarize the major results of each chapter and discuss importance of each finding together with policy implementations. Finally, future research plans will be discussed given the contribution of this dissertation. 


\title{
Chapter 2
}

\section{Efficient Taxes for Cost Revelation in a Price and Quantity Constrained}

\section{Electric Power Market.}

\begin{abstract}
We analyze an electricity market that does not clear. The system operator satisfies fixed demand at a fixed price, and attempts to minimize "cost" as indicated by independent generators' supply bids. No equilibrium exists in this situation, and the operator lacks information sufficient to minimize actual cost. As a remedy, we propose a simple efficient tax mechanism. With the tax, Nash equilibrium bids still diverge from marginal cost but nonetheless provide sufficient information to minimize actual cost, regardless of the tax rate or number of generators.
\end{abstract}




\subsection{Introduction}

Markets require flexible prices to clear efficiently. Most modern wholesale electricity markets experience price rigidities such as price caps that bind principally in periods of peak demand and, often, system stress. When prices are rigid, an exogenously determined, price-inelastic load must be satisfied at a fixed price. This paper provides a stylized model of such a system, in which both price and market load are exogenous. More generically, it addresses the breakdown of a bidding system in which prices paid are not affected by bids, and proposes a simple remedy for the breakdown. This breakdown may occur more often in coming years, as transitional, hybrid regulated markets develop in a U.S. electricity industry traumatized by the California market debacle of 2000 .

Given a fixed price and required quantity, the system operator (SO) can not rely on market forces to allocate production automatically among the generators available on the system. Instead, the SO must decide administratively how much each generator should produce. In a well designed system, the SO will do so in a manner that minimizes the cost of production. In the traditional vertically integrated system, this task was fairly easy because the SO had certain knowledge of the actual costs of all generators. Increasingly, however, the generation resources of the system are owned by independent firms whose costs are indicated only through voluntary, and strategically determined, bids. The SO needs a mechanism to identify and dispatch the most efficient generation resources, especially at times of system stress, when price signals are most likely be distorted by regulatory intervention.

A growing academic literature has developed recently concerning the design of electricity markets (see e.g. Wilson (2002) and Stoft (2002) for surveys and outlines of the major issues). Regulatory authorities have taken a keen practical interest in this problem as well (FERC 2002). There has been some research about the use of bids to improve the performance of 
the system in the very short run (e.g. Cardell, 1997 who assumes that sellers bid their costs truthfully), but most work has concentrated on day-ahead and real-time energy markets that clear. In contrast, the present research focuses on cost-minimization in markets that do not clear because of price rigidities and require the intervention of a system operator to stay in balance.

We focus on the problem of determining the low-cost mix of suppliers' output in the absence of direct cost information. The only indication of the generator's cost is its bid. In our model, firms bid supply functions that are of the same functional form as the true cost functions, which reflects the reality that production technologies are well-known, but other cost factors such as fuel costs, may be proprietary. Generators choose the parameters of their bid functions for strategic reasons, in light of their expectations as to the reactions of the SO and competitors. Similarly, in the supply function equilibrium (SFE) literature, beginning with Klemperer and Meyer (1989) and adapted to electricity markets by Green and Newbery (1992) and more recently by Baldick and Hogan (2001, 2002), firms also bid supply functions strategically. However, we employ a different payment mechanism, and our focus is different from the papers in the SFE literature. We focus on information asymmetries between the operator and the generators, and on demonstrating a mechanism that will reveal merit order without market price adjustments. In our market, price is fixed externally, so participants use bids only to obtain the desired market share.

This element of fixed price sets this paper apart from the electricity market power literature, reviewed in Wolfram (1998), and later analysis of market power in the presence of transmission constraints by, e.g., Joskow and Tirole (2000), Borenstein et al. (2000), and Willems (2002). In our model, market power manifests itself, not in the manipulation of price, but in the manipulation of cost "information" with the objective of obtaining optimal market share. Taking transmission constraints into account is beyond the scope of this paper, 
as they complicate the analysis by adding another vector of costs for the SO to consider, but do not change the essential findings of our analysis.

We find that no set of Nash equilibrium bids exist in our model, and that generators' bids diverge widely from actual marginal costs. As a remedy, we propose a simple tax mechanism that induces bidding that provides sufficient information for will allow the SO to minimize the total cost of production. Interestingly, these bids, though efficient, diverge from true marginal cost.

Although for purposes of exposition we focus on a two-generator market with quadratic cost functions, we show that our results hold for any number of generators, with weak restrictions on the general convex cost functions.

We focus on the problem of overcapacity (i.e., the SO must choose among generators who wish to produce more in aggregate than the load requires), but a symmetric result occurs if insufficient voluntary generation is available at the fixed price.

The paper's structure is as follows. In the next section we will introduce the market model, including market participants and rules of the game. After that, we show that the generators' bids will depart from true costs, and demonstrate the nonexistence of a Nash equilibrium in the model without taxes. Next, we introduce the tax mechanism and show that it will create a Nash equilibrium in the market, which we demonstrate to be efficient. Finally, through simple examples and simulations we explore the properties of the mechanism and demonstrate its performance for both linear and quadratic costs. 


\subsection{The Model}

Suppose there are $n$ independent generators available in a real-time energy market. Assume that they do not cooperate with each other when they make decisions. Consumers create an exogenous load $Q$ on the system, which must be satisfied in real time. Each generator is paid a price, $P$, for its output, determined exogenously, perhaps by a price cap. This price is not affected by either the bid or the quantity that the generator produces.

Although each generator takes market price and quantity as fixed, its bid determines the quantity of energy that the System Operator (SO) allows it to produce. The SO seeks to minimize the true cost of production. In pursuit of this goal, it may use an algorithm that minimizes the total "bidded" cost of serving the load, treating the generators' bids as though they were the actual costs. The SO knows the market demand for energy, and the bids of each generator, and it takes into account the rational response of generators to its dispatch algorithm. We investigate the SO's prospects for success in minimizing bidded costs.

For simplicity, assume there are only two generators, designated G1 and G2. The market then looks as follows:

The System Operator collects bids (characterized by bid supply function vectors $a_{1}$ and $a_{2}$ ) and uses them to assign production levels $\left(x_{1}\right.$ and $\left.x_{2}\right)$ for each of the generators.

\section{Generator's problem.}

Each generator wants to produce at the level $x_{i}$ that maximizes its profit, $\pi\left(x_{i}\right)=$ $P x_{i}-C\left(x_{i}, \alpha_{i}\right)$, where $C(\cdot)$ is its cost function, and $\alpha_{i}$ is its associated parameter vector. Generators bid by submitting a bidded cost function $B_{i}\left(x_{i}, a_{i}\right)$, which we assume differs from $C(\cdot)$ only if $a_{i} \neq \alpha_{i}$. Generators determine their bids strategically, so the bids may differ 


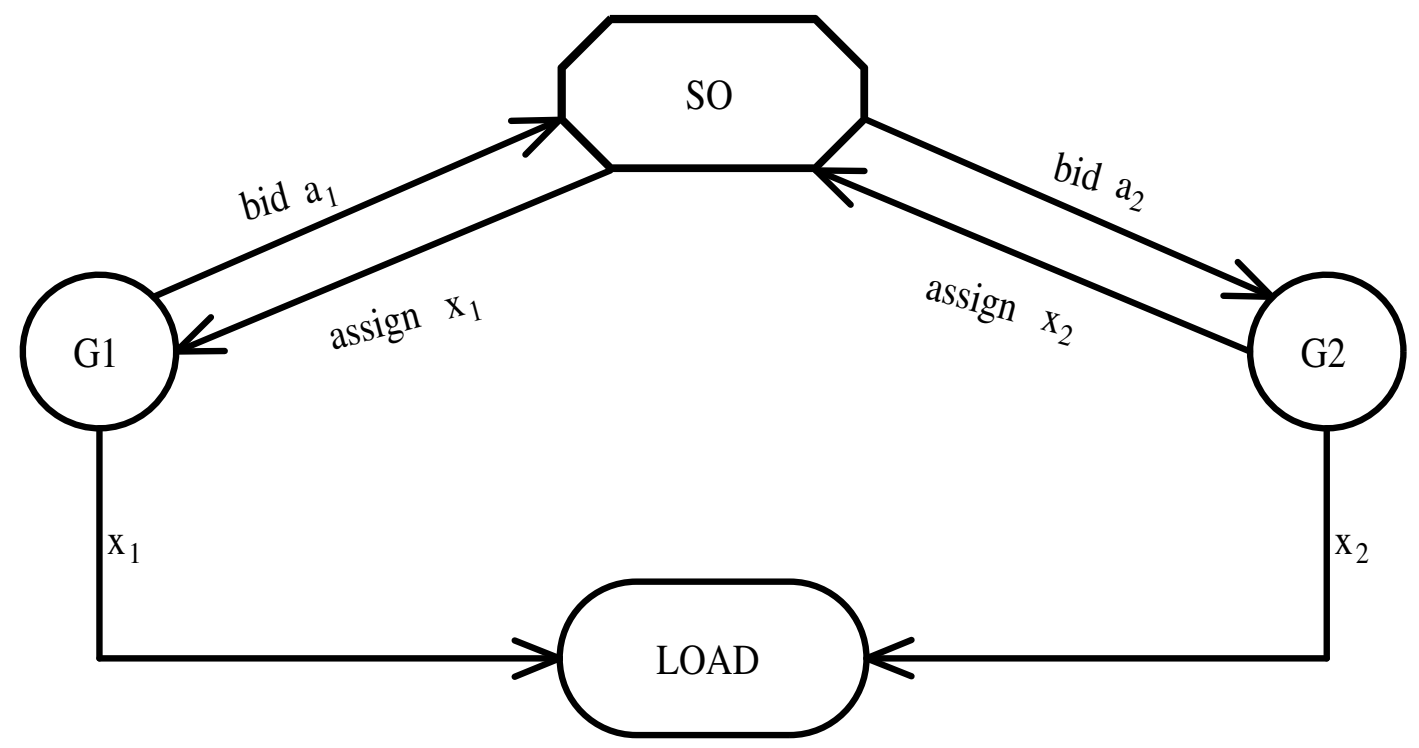

Figure 2.1: Power Market system.

from actual costs.

By manipulating its bid parameter vector $a_{i}$ the generator can influence the SO's dispatch decision. The purpose of the successful bid for a generator is to induce the SO to assign it the level of production that maximizes its profit. For example, if cost functions take the form

$$
C_{i}\left(x_{i}, \alpha_{i}\right)=\alpha_{i 1} x_{i}+\alpha_{i 2} x_{i}^{2}
$$

then generator $i$ will attempt to induce the SO to assign it to produce

$$
x_{i}^{*}=\frac{P-\alpha_{i 1}}{2 \alpha_{i 2}}
$$




\section{The System Operator's Problem.}

The system operator (SO) monitors the load $\mathrm{Q}$, and consults its dispatch function to determine how much power will be supplied by each of the generators. We assume that the System Operator is seeking to maximize social welfare. With quantity of output fixed by inelastic demand, this is equivalent to minimizing the total cost of generation, subject to the requirement to satisfy the load. First order conditions for this cost minimizing objective function require marginal costs to be equal across all generators.

$$
\begin{array}{r}
\frac{\partial C_{i}(\cdot)}{\partial x_{i}}=\frac{\partial C_{j}(\cdot)}{\partial x_{j}} \\
\text { and } \quad \sum_{i=1}^{n} x_{i}=Q
\end{array}
$$

Unfortunately, the SO does not have sufficient information to achieve (2.2). The problem is that the SO has no direct information about marginal costs; marginal cost is proprietary information for the generators, and the only information the generators provide the SO is contained in their bids. The SO can follow any dispatch algorithm that it likes, but without information about true marginal costs it will not be able to maximize social welfare. Instead, it will be subject to manipulation by the generators' strategic bidding.

\subsection{Strategic Bidding and Market Instability}

If all generators were to bid their true marginal cost parameters $\alpha$, the SO would easily be able to achieve the cost-minimizing allocation of output among the generators. However, rather than reveal its true cost parameters, each generator will seek to bid strategically, and 
their bids will generally not be compatible with system cost-minimization. In fact, without modification the market will not achieve any stable equilibrium. To see this, substitute (2.1) into (2.2), bearing in mind that both $P$ and $Q$ are fixed. It is clear that the generators will not in aggregate voluntarily supply the correct amount of output $\left(\sum_{i=1}^{n} x_{n} \neq Q\right)$ unless the cost parameters happen to take extremely fortuitous values; i.e., unless

$$
\sum_{i=1}^{n} \frac{\left(P-\alpha_{i 1}\right)}{2 \alpha_{i 2}}=Q
$$

Thus, the desires of the generators will not be compatible with the most basic requirement of the system to balance load and generation, and whenever the system is in balance at least one generator will find it advantageous to change its bid, and hence its allocation $x_{i}$.

It follows that it will not, in general, be in the interest of the generators to reveal their true costs, since by doing so they will not induce the SO to maximize their profits. Suppose, for example, that there are two generators, and the SO naively chooses to minimize the sum of the bidded costs of the generators:

$$
\begin{gathered}
\min _{\left\{x_{1} \ldots x_{n}\right\}} \sum_{i=1}^{n} B_{i}\left(x_{i}, a_{i}\right) \\
\text { s.t. } \sum_{j=1}^{n} x_{j}=Q
\end{gathered}
$$

In this case, the $\mathrm{SO}$ will assign generator $\mathrm{G} 1$ to produce

$$
\hat{x}_{1}=\frac{\left(a_{21}-a_{11}+2 a_{22} Q\right)}{2\left(a_{12}+a_{22}\right)}
$$

Knowing that this is the SO's algorithm, G1 will substitute (2.4) into its own profitmaximization condition (2.1), and will choose bid parameters $a_{i}$ such that 


$$
\frac{\left(P-\alpha_{i 1}\right)}{2 \alpha_{i 2}}=\frac{\left(a_{21}-a_{11}+2 a_{22} Q\right)}{2\left(a_{12}+a_{22}\right)}
$$

Note that G1 chooses two parameters $\left(a_{11}, a_{12}\right)$, while the other terms in equation $(2.5)$ are fixed from G1's point of view. Because (2.5) is a linear equation with two unknowns, there exist an infinite number of ordered pairs $\left(a_{11}, a_{12}\right)$ that solve it. Also, G1's solution set depends on G2's bid $a_{22}$, and vice versa. Thus, each will change its own bid when the other's bid changes, and any solution of (2.5) will be a profit-maximizing strategic response of G1 to G2's bid. There will be no equilibrium unless both can simultaneously maximize profits; i.e., unless

$$
\sum_{i=1}^{2} \frac{\left(P-\alpha_{i 1}\right)}{2 \alpha_{i 2}}=Q
$$

which will only be true for particular combinations of the fixed parameters $Q, \alpha_{i 1}$, and $\alpha_{i 2}$. Hence, there is generally no Nash equilibrium for this market.

To get some intuition for the outcome, suppose that the price $P$ exceeds marginal cost $\left(P>\alpha_{i 1}+2 \alpha_{i 2} x_{i}\right.$ for $\left.x_{i} \leq Q\right)$, for both generators. In this case, each generator will seek to increase its market share to unity, and in pursuit of this objective will reduce its bidded cost of producing $Q$ below its opponent's bid, and consequently bids will decline without bound. Conversely, if $P$ is less than marginal cost for both generators, they will raise their bids without bound. In either case, the SO will get no information about relative costs from the generators' bids, and will not be able to minimize the cost of serving load. There will be no Nash Equilibrium in this market, and the dispatch rate of each generator will fluctuate without regard to production cost. To remedy this situation, the SO will need to introduce some additional incentive to induce bidders to provide better cost information. 


\subsection{Taxes}

Without knowledge of actual costs, how can the SO minimize true system cost when generators bid strategically? It turns out to be sufficient to introduce a tax rate $t \in(0,1]$ on the difference between the bid and the market price. Note that if $t=1$, the generators are paid "as bid". For generators bidding below the price P, this tariff can be thought of as a tax on reported profits. It creates a penalty for strategic bidding, and hence a tradeoff. On the one hand, by bidding low the generator can induce the SO to increase its production share. On the other hand, a lower bid implies a higher tax payment. ${ }^{1}$

\section{The Generator's Problem}

Suppose there are $n$ generators and $m$ parameters in each generator's bid (and cost) functions. If all generators pay the same fixed tariff rate $t \in(0,1]$, then $t\left[P x_{i}\left(a_{i}\right)-B_{i}\left(x\left(a_{i}\right), a_{i}\right)\right]$ is $G_{i}$ 's tax payment, and the net (after-tax) profit for generator $G_{i}$ is

$$
\pi_{i}\left(a_{i}\right)=P x_{i}\left(a_{i}, a_{-i}\right)-C_{i}\left(x_{i}\left(a_{i}, a_{-i}\right)\right)-t\left[P x_{i}\left(a_{i}, a_{-i}\right)-B_{i}\left(x_{i}\left(a_{i}, a_{-i}\right), a_{i}\right)\right]
$$

where $a_{-i}$ is the $(n-1) \times m$ matrix of other generators' bid parameters. For notational simplicity, in the following discussion we will suppress the $a_{-i}$ term, but each generator is well aware that its own dispatch rate $x_{i}$ depends on the bids of the other generators $a_{-i}$, as well as its own bid vector $a_{i}$.

Generator $i$ will bid the $m$-vector $a_{i}$ that it thinks will maximize its own profit $\pi_{i}$ given the anticipated dispatcher response and assuming other generators' bids will remain constant.

\footnotetext{
${ }^{1} \mathrm{~A}$ similar situation applies if there is insufficient energy offered at the market price, except that in this case the tax will manifest as an efficient subsidy.
} 
Thus, Generator $i$ 's objective function is

$$
\max _{a_{i}} \pi_{i}\left(x_{i}\left(a_{i}\right), a_{i}\right)=P x_{i}\left(a_{i}\right)-C_{i}\left(x_{i}\left(a_{i}\right), \alpha_{i}\right)-t\left[P x_{i}\left(a_{i}\right)-B_{i}\left(x_{i}\left(a_{i}\right), a_{i}\right)\right]
$$

Profit maximization gives rise to $m$ first order condition equations, which can be written in vector notation as

$$
\frac{\partial \pi_{i}(\cdot)}{\partial a_{i}}=P \frac{\partial x_{i}\left(a_{i}\right)}{\partial a_{i}}-\frac{\partial C_{i}(\cdot)}{\partial x_{i}\left(a_{i}\right)} \frac{\partial x_{i}\left(a_{i}\right)}{\partial a_{i}}-t\left[P \frac{\partial x_{i}\left(a_{i}\right)}{\partial a_{i}}-\frac{\partial B_{i}(\cdot)}{\partial x_{i}\left(a_{i}\right)} \frac{\partial x_{i}\left(a_{i}\right)}{\partial a_{i}}-\frac{\partial B_{i}(\cdot)}{\partial a_{i}}\right]=0
$$

or

$$
\frac{\partial C_{i}(\cdot)}{\partial x_{i}\left(a_{i}\right)} \frac{\partial x_{i}\left(a_{i}\right)}{\partial a_{i}}=\left[(1-t) P+t \frac{\partial B_{i}(\cdot)}{\partial x_{i}\left(a_{i}\right)}\right] \frac{\partial x_{i}\left(a_{i}\right)}{\partial a_{i}}+t \frac{\partial B_{i}(\cdot)}{\partial a_{i}}
$$

The $m$-vector $\frac{\partial x_{i}\left(a_{i}\right)}{\partial a_{i}}$ is the generator's anticipation of the reaction of the SO to a change in its bid parameter vector $a_{i}$. The generator will arrive at this vector through experience, or by the SO providing a credible value, as further discussed below. As long as $\frac{\partial x_{i}\left(a_{i}\right)}{\partial a_{i}}$ has no zero elements, we can define a vector $\left[1 / \frac{\partial x_{i}\left(a_{i}\right)}{\partial a_{i}}\right]$ whose elements consist of the multiplicative inverses of the elements of $\frac{\partial x_{i}\left(a_{i}\right)}{\partial a_{i}}$. Using this notation, the generator's first-order profitmaximization condition becomes

$$
\frac{\partial C_{i}(\cdot)}{\partial x_{i}\left(a_{i}\right)}=(1-t) P+t \frac{\partial B_{i}(\cdot)}{\partial x_{i}\left(a_{i}\right)}+\left[t \frac{\partial B_{i}(\cdot)}{\partial a_{i}}\right]\left[1 / \frac{\partial x_{i}\left(a_{i}\right)}{\partial a_{i}}\right]
$$

The generator can manipulate equation system (2.6) by manipulating the elements of $a_{i}$. (Note that there are $m$ equations and $m$ control parameters $a_{j i}$ per generator). The left- 
hand side (marginal cost) and the first term on the right-hand side of (2.6) are constant across the $m$ equations, and also invariant to changes in $a_{i}$. The second term on the righthand side ( $t$ times marginal bidded cost) is also constant across the m equations, although it varies with $a_{i}$. Therefore, $\frac{\partial B_{i}(\cdot)}{\partial a_{i}}\left[1 / \frac{\partial x_{i}\left(a_{i}\right)}{\partial a_{i}}\right]$ is also constant across all equations when the generator is profit-maximizing. Equation (2.6) may be rearranged to show that the difference between the price $P$ and generator $i$ 's marginal cost is $t$ times the difference between price and marginal bidded cost, plus the third term on the right-hand side of (2.6).

\section{The System Operator's Problem.}

As before, the System Operator seeks to maximize social welfare by minimizing the total cost of generation, which requires marginal costs to be equal across all generators, as in equation (2.2). Again, the SO has no direct information about marginal costs, but the tax creates a link between bids and costs that allows the SO to infer marginal cost from bids, using equation (2.6). Substituting (2.6) into (2.2), the SO's optimal economic dispatch problem is to solve

$$
\left[(1-t) P+t \frac{\partial B_{i}(\cdot)}{\partial x_{i}}\right]\left[\frac{\partial x_{i}\left(a_{i}\right)}{\partial a_{i}}\right]+t \frac{\partial B_{i}(\cdot)}{\partial a_{i}}=\left[(1-t) P+t \frac{\partial B_{j}(\cdot)}{\partial x_{j}}\right]\left[\frac{\partial x_{j}\left(a_{j}\right)}{\partial a_{j}}\right]+t \frac{\partial B_{j}(\cdot)}{\partial a_{j}}
$$

for all generators $i$ and $j$ while satisfying load. Because $(1-t) P$ is already a constant across all generators and $t$ is a common factor in the rest of equation, the optimal economic dispatch solution does not depend on either $P$ or $t$.

Thus, the SO must choose an n-vector $\mathrm{x}$ that solves the system of $m(n-1)+1$ equations

$$
\frac{\partial B_{i}(\cdot)}{\partial x_{i}}+\left[\frac{\partial B_{i}\left(x_{i}, a_{i}\right)}{\partial a_{i}}\right]\left\{\frac{1}{\partial x_{i} / \partial a_{i}}\right\}=\frac{\partial B_{j}(\cdot)}{\partial x_{j}}+\left[\frac{\partial B_{j}\left(x_{j}, a_{j}\right)}{\partial a_{j}}\right]\left\{\frac{1}{\partial x_{j} / \partial a_{j}}\right\} \quad \forall i, j
$$




$$
\text { subject to } \sum_{k=1}^{n} x_{k}=Q
$$

in order to minimize the cost of serving the load.

Satisfying (2.7) will achieve cost minimization, however, only in Nash equilibrium. To see this, note that each generator's profit maximization condition (2.6) depends on the dispatch allocation $x_{i}$ that it anticipated when it set its bid $a_{i}$. If its actual allocation differs from what it anticipated, then (2.6) will not be satisfied, and (2.2) will not be equivalent to (2.7). Thus, by satisfying (2.7), the SO will simultaneously achieve both profit maximization (2.6) for all generators and cost minimization (2.2) for the system only if each generator's actual allocation $x_{i}$ is the same as its anticipated allocation; i.e., only if the system is in Nash equilibrium.

\subsection{Reaching Cost Minimizing Equilibrium}

To proceed, the SO first declares a tax rate $t$, price $P$, and load level $Q$. It collects bids from the generators in the form of an $m \times n$ matrix of bid parameters $a$. Based on $a$, it then announces a dispatch allocation $n$-vector, $x$, that satisfies condition (2.7), and adjusts all generators' outputs accordingly. Generators use equation (2.6) to reassess their bids in light of the allocation, and then offer new bids if they believe they can increase their profits by doing so. Equilibrium is reached when all generators are satisfied with their bids and allocations.

A key unknown variable in the calculation of (2.6) and (2.7) is the SO's bid response function $\frac{\partial x_{i}\left(a_{i}\right)}{\partial a_{i}}$. Clearly, the SO must know what value the generator ascribes to $\frac{\partial x_{i}\left(a_{i}\right)}{\partial a_{i}}$ in order to solve (2.7). One way that this might occur is for the SO to simply follow a rule, such 
as bidded cost minimization, whose implications the generator will learn through trial and error. Another way is for the SO to simply announce a credible rule governing its bid response function and thereby reduce uncertainty and speed up the equilibrating process.

There is one class of rules that is consistent with bidded cost minimization and especially simplifies the process. Recall from (2.6) that profit maximization for generator $i$ requires that $\left[\frac{\partial B_{i}(\cdot)}{\partial a_{i k}}\right]\left\{\frac{1}{\partial x_{i}\left(a_{i}\right) / \partial a_{i k}}\right\}$ be equal across all of its parameters $a_{i k}, k=1, \ldots m$, meaning that $\frac{\partial B_{i}(\cdot)}{\partial a_{i k}}$ and $\frac{1}{\partial x_{i}\left(a_{i}\right) / \partial a_{i k}}$ will be in fixed proportion in equilibrium. To ensure the fixed proportion, the SO can simply announce a rule that ties $\frac{1}{\partial x_{i}\left(a_{i}\right) / \partial a_{i k}}$ directly to $\frac{\partial B_{i}(\cdot)}{\partial a_{i k}}$. For example, the rule

$$
\frac{\partial x_{i}\left(a_{i}\right)}{\partial a_{i k}}=-\left(\frac{\partial B_{i}\left(x_{i}, a_{i}\right)}{\partial a_{i k}}\right)
$$

sets the proportionality equal to -1 . Other rules may be devised, but (2.8) has the advantage of simplicity. It is also credible, both because an increase in bidded cost always causes the dispatch allocation to fall, and because a change in the bid parameter has an effect on the dispatch allocation that is proportional to its effect on bidded cost. Substituting (2.8) into (2.7) implies that in equilibrium the $\mathrm{SO}$ will be able to minimize the cost of production by simply minimizing bidded cost, i.e., by setting $\frac{\partial B_{i}(\cdot)}{\partial x_{i}}=\frac{\partial B_{j}(\cdot)}{\partial x_{j}}$ for all generators $i$ and $j$. Adopting rule (2.8) and substituting it into (2.6) implies that each generator will choose a parameter vector $a_{i}$ such that

$$
\frac{\partial B_{i}\left(x_{i}, a_{i}\right)}{\partial x_{i}}=P+t-\frac{1}{t}\left[P-\frac{\partial C_{i}\left(x_{i}, \alpha_{i}\right)}{\partial x_{i}}\right]
$$

Note that (2.9) is a single equation with $m$ control variables in the vector $a_{i}$. In general, there may be more than one parameter vector $a_{i}$ per generator that satisfies equation (2.9), 
but for linear and other well-behaved functions there will be at least one parameter vector that satisfies it.

Referring to the previous example of two generators, substituting the quadratic cost and bid functions into generator $i$ 's profit-maximization condition (2.9) and solving for $x_{i}$ yields the profit-maximizing level of output for generator $i$ :

$$
x_{i}^{*}=\frac{(1-t) P+t a_{i 1}-\alpha_{i 1}-t}{2\left(\alpha_{i 2}-t a_{i 2}\right)}
$$

Clearly, for any dispatch allocation $x_{i}$ and cost parameter vector $\left(\alpha_{i 1}, \alpha_{i 2}\right)$ there will be a class of bid parameter vectors $\left(a_{i 1}, a_{i 2}\right)$ consistent with profit maximization. Using equation (2.7) and rule (2.8), the SO will apply equation (2.4), as before, to determine optimal dispatch for generator $i$ :

$$
\hat{x}_{i}=\frac{a_{j 1}-a_{i 1}+2 a_{j 2} Q}{2\left(a_{i 2}+a_{j 2}\right)}
$$

Setting $x_{i}^{*}=\hat{x}_{i}$ yields the function that generator $i$ will employ in responding to generator j's bid:

$$
\frac{(1-t) P+t a_{i 1}-\alpha_{i 1}-t}{2\left(\alpha_{i 2}-t a_{i 2}\right)}=\frac{a_{j 1}-a_{i 1}+2 a_{j 2} Q}{2\left(a_{i 2}+a_{j 2}\right)}
$$

Given generator $j$ 's bid of $\left(a_{j 1}, a_{j 2}\right)$, generator $i$ will pick a parameter vector $\left(a_{i 1}, a_{i 2}\right)$ that will satisfy (2.11). In Nash equilibrium, the allocation vector will be both profit-maximizing for all generators and bidded-cost minimizing. Thus, for Nash equilibrium to exist there must exist at least one set of bid parameters such that 


$$
\sum_{i=1}^{2} \frac{(1-t) P+t a_{i 1}-\alpha_{i 1}-t}{2\left(\alpha_{i 2}-t a_{i 2}\right)}=Q
$$

Note that, in contrast to (2.5a), equation (2.12) depends on the bid parameters $a$, and hence can be satisfied through adjustments of bids. Thus, any set of bid parameters $a$ that satisfies (2.11) for both $i$, and also satisfies (2.12), will constitute a Nash equilibrium. All Nash equilibria will have the same allocation vector $x$, since only one allocation vector is consistent with cost minimization. If the number of bid parameters, $m$, per generator exceeds one then there will be well-defined, but infinite set of feasible values of $a$ that will be consistent with the cost-minimizing allocation vector $x$. The $\mathrm{SO}$ can restrict bids, perhaps restricting bidding to one parameter only, in order to restrict the space of feasible Nash equilibrium bids to a point. In the quadratic example above, if the SO forces $a_{i 1}=0$ then the Nash Equilibrium value of $a_{i 2}$ becomes a complicated, but deterministic, function of $P, Q, t, a_{j 2}$, and the cost parameters.

\subsection{Examples of Cost functions for two generators}

\section{Linear Costs}

A market with two generators with linear cost and bid functions provides a simple example that illustrates the function of the efficient tax. Suppose that the cost and bid functions of generator $i\left(\mathrm{G}_{i}\right)$ are, respectively, $C_{i}=\alpha_{i} x_{i}$ and $B_{i}=a_{i} x_{i}$.

For simplicity, assume that either of the generators could supply the entire market on its own, and either would profit from doing so (i.e., $P>\alpha_{i}$ ). In this case, the SO's task is simply to use the bid parameters $a_{i}$ to determine which generator has the lower true cost 
parameter $\alpha_{i}$, and allocate all production to that generator. If there is no tariff, the profit function of generator $i$ is

$$
\pi_{i}=P x_{i}-\alpha_{i} x_{i}
$$

and there will be no Nash equilibrium because each generator will attempt to underbid the other, and the bids will decrease without bound.

If, on the other hand, the SO institutes a tariff rate $t$ on the winner's apparent profit, then the winner's actual profit will be

$$
\pi_{i}=P x_{i}-\alpha_{i} x_{i}-t\left(P x_{i}-a_{i} x_{i}\right)
$$

Suppose that $\alpha_{1}<\alpha_{2}$, so that G1 is the efficient producer. In Nash equilibrium, each player bids the parameter $a_{i}$ that maximizes its own profit, given the other generators' actual bids. If the price is fixed, then G1's potential profit will always exceed G2's potential profit, because G1's costs are lower. From the profit function, it is apparent that generator $i$ obtains positive economic profit if and only if

$$
a_{i}>(1 / t)\left[\alpha_{i}-(1-t) P\right]
$$

Because $\alpha_{1}>\alpha_{2}$, there will always exist bids that would yield a positive profit for G1, but a negative or zero profit for G2. There can be no Nash equilibrium, therefore, where the higher-cost generator G2 wins the bid. Instead, Nash equilibrium in this simple market occurs where 


$$
a_{2}=(1 / t)\left[\alpha_{2}-(1-t) P\right]
$$

and

$$
a_{1}=(1 / t)\left[\alpha_{2}-(1-t) P\right]-\varepsilon
$$

where $\varepsilon$ is the smallest increment allowed between bids. G1 is satisfied with this outcome because it is allowed to produce the amount that maximizes its profit, and a higher bid would lose to G2. G2 is also satisfied, because when it produces nothing it also has a zero profit, whereas if it lowers its bid below G1's bid it will produce at a loss.

Note that the market result is efficient, and therefore the SO is satisfied, regardless of the level of $t$. In fact, changes in $t$ will not even affect the tariff collected in the linear case. Substituting the bid into the profit function (and neglecting $\varepsilon$ ), the tariff collected in this simple case will be $\left(P-\alpha_{2}\right) Q$, regardless of the tariff rate $t$. Also, G1's profit will be the same as in a second-price or Vickrey auction: $\left(\alpha_{2}-\alpha_{1}\right) Q$. Changes in $t$ will, however, affect the NE levels of the bids. Bids will even become negative if $t P<\left(P-\alpha_{2}\right)$, but the tariff will create a lower limit to their decline.

\section{Quadratic Costs}

A somewhat more realistic but complicated case is that of two generators with quadratic costs and bids

$$
C_{i}\left(x_{i}\right)=\alpha_{i} x_{i}^{2}+\beta_{i} \quad i=1,2
$$


where $\alpha_{i}$ is a marginal cost parameter and $\beta_{i}$ represents fixed costs.

$$
B_{i}\left(x_{i}\right)=a_{i} x_{i}^{2}+b_{i}
$$

If Generator 2 (G2) bids $a_{2}$, Generator 1 (G1) will adjust its bid $a_{1}$ to maximize its own profit.

$$
a_{1}=\arg \max \left[\pi_{1}\left(a_{1}, a_{2}\right)\right]
$$

Similarly, G2 will adjust its own bid $a_{2}$, so as to maximize its own net profit conditional on G1's bid of $a_{1}$ and the SO's assigned production level $x_{2}\left(a_{1}, a_{2}\right)$. Thus,

$$
a_{2}=\arg \max \left[\pi_{2}\left(a_{1}, a_{2}\right)\right]
$$

In Nash equilibrium, neither generator will be able to improve its profit by changing its bid. If the SO minimizes bidded cost of generation, subject to the total energy constraint:

$$
\min _{x} \sum_{i=1}^{2} a_{i} x_{i}^{2}+b_{i}+\lambda\left(Q-x_{1}-x_{2}\right)
$$

then its dispatch function satisfies the first order conditions $2 a_{i} x_{i}-\lambda=0$.

The Nash Equilibrium (NE) for this market occurs where bids $a_{1}$ and $a_{2}$ solve the following system of equations: 


$$
\left\{\begin{array}{l}
P-2 \alpha_{1} x_{1}\left(a_{1}, a_{2}\right)-t\left[P-2 a_{1} x_{1}\left(a_{1}, a_{2}\right)-\frac{x_{1}^{2}\left(a_{1}, a_{2}\right)}{\partial x_{1}\left(a_{1}, a_{2}\right) / \partial a_{1}}\right]=0 \\
P-2 \alpha_{2} x_{2}\left(a_{1}, a_{2}\right)-t\left[P-2 a_{2} x_{2}\left(a_{1}, a_{2}\right)-\frac{x_{2}^{2}\left(a_{1}, a_{2}\right)}{\partial x_{2}\left(a_{1}, a_{2}\right) / \partial a_{2}}\right]=0
\end{array}\right.
$$

where $x_{1}(\cdot)$ and $x_{2}(\cdot)$ are found endogenously by the SO as a solution to its dispatch algorithm. We have solved the system in a simulated market and generated the response functions (2.14) in $a_{1}, a_{2}$ space, shown in Figure 2.2.

If Generator 2 bids $a_{2}$, G1's response function $a_{1}=R_{1}\left(a_{2}\right)$ yields the bid that would maximize Generator 1's net profit. Correspondingly, $R_{2}\left(a_{1}\right)$ is the best response of the second generator given the bid $a_{1}$ of the first generator. The point of intersection represents the NE solution.

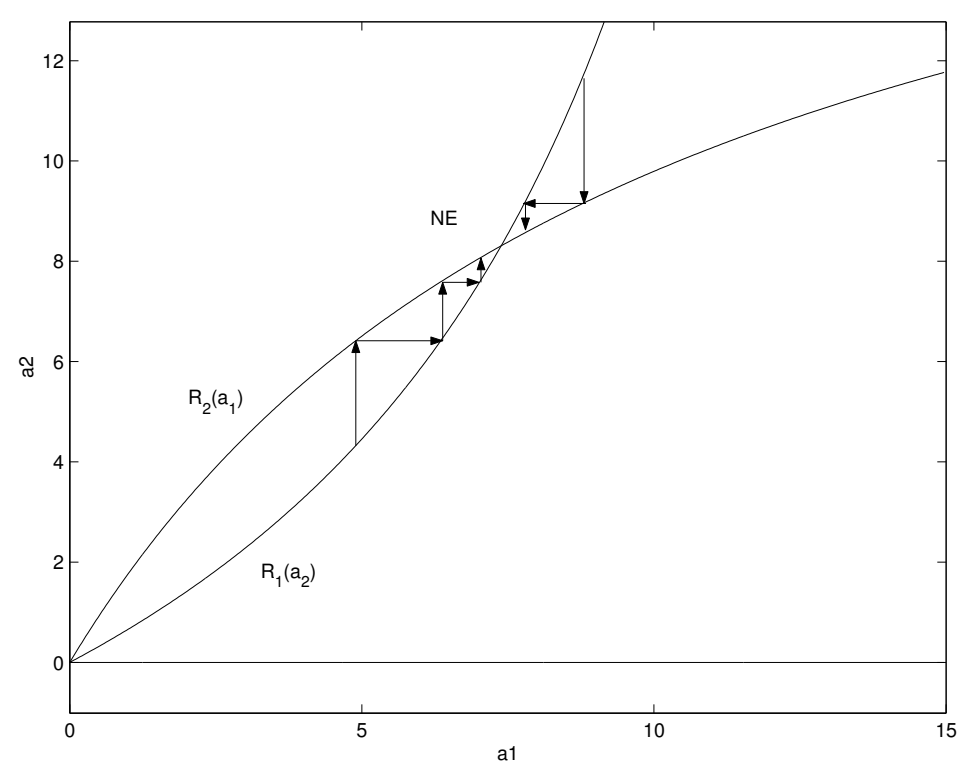

Figure 2.2: Simulation Results: Nash Equilibrium and Transitional Dynamics.

Dynamic analysis shows that if cost functions are convex then the NE is stable; i.e., that any movement away from NE will automatically create incentives that move the generators back to NE. In Figure 2.2, the arrows show these dynamics. 
For example, if G1 sets $a_{1}=5$, then G2 will respond by increasing $a_{2}$ to approximately 6.5. Because of G2's higher bid, the SO will assign G1 to produce more (and pay more tariff) than G1 had hoped, which will induce G1 to raise $a_{1}$ some more. This higher bid by G1 will cause the SO to assign more output (and therefore a higher tariff payment) to G2 than it had planned on, which will induce G2 to raise its bid, and so on.

This result is also efficient. To see the efficiency of the NE, substitute the SO's bid minimization condition in the profit function of both generators

$$
\left\{\begin{array} { l } 
{ P - 2 \alpha _ { 1 } x _ { 1 } ( a _ { 1 } , a _ { 2 } ) - t [ P - \frac { \lambda } { 2 } ] = 0 } \\
{ P - 2 \alpha _ { 2 } x _ { 2 } ( a _ { 1 } , a _ { 2 } ) - t [ P - \frac { \lambda } { 2 } ] = 0 } \\
{ x _ { 1 } + x _ { 2 } = Q }
\end{array} \Rightarrow \left\{\begin{array} { l } 
{ 2 \alpha _ { 1 } x _ { 1 } ( \cdot ) = 2 \alpha _ { 2 } x _ { 2 } ( \cdot ) } \\
{ x _ { 1 } + x _ { 2 } = Q }
\end{array} \Leftrightarrow \left\{\begin{array}{l}
\frac{\partial C_{1}\left(x_{1}\right)}{\partial x_{1}}=\frac{\partial C_{2}\left(x_{2}\right)}{\partial x_{2}} \\
x_{1}+x_{2}=Q
\end{array}\right.\right.\right.
$$

NE thus results in efficient production levels for both generators

$$
\begin{aligned}
& x_{1}\left(Q, a_{1}^{N E}, a_{2}^{N E}\right)=\frac{\alpha_{2} Q}{\alpha_{1}+\alpha_{2}} \\
& x_{2}\left(Q, a_{1}^{N E}, a_{2}^{N E}\right)=\frac{\alpha_{1} Q}{\alpha_{1}+\alpha_{2}}
\end{aligned}
$$

just as would have occurred if both generators had bid their true marginal costs.

\subsection{Conclusions}

Information flow in electricity markets is increasingly decentralized, yet the importance of efficient operation is undiminished. A system operator may have to make an administrative dispatch decision based on bids rather than costs, to serve an inelastic load at a price fixed by 
regulation or other constraints. We show that under these circumstances a stylized market in which generators submit supply function bids will not provide sufficient information for the system operator to minimize the cost of meeting load.

We propose a simple remedy in the form of a tax, which produces incentive-compatible bids that allow the SO to minimize the cost of satisfying the load without needing to know the true parameters of the generators' cost functions. Despite its simplicity, the tax has very strong short-run efficiency implications. It allows the operator to identify the leastcost production mix, and thereby minimize the total cost of satisfying the load. Generators obtain profit equal to the spread between price and the cost of most efficient losing bidder. Because market output is fixed, efficiency does not require a large number of competitive bidders; the equilibrium bids produce a fully efficient outcome even in a duopoly.

Our results are not relevant to well-behaved markets that reliably clear, but such wellbehaved electricity markets do not exist everywhere, in the United States today. Large portions of the country are still under the sway of traditional utilities, and even those sections of the country that have established functioning competitive markets hesitate to rely solely upon them in the wake of the California debacle of 2000. Most new generation facilities are independently owned, so information does not flow freely. This paper therefore addresses issues that system designers, regulators, operators, and market participants will be grappling with for the foreseeable future.

We have left open many interesting questions related to the long-term implications of the tariff mechanism. Imposing an efficient tax has the side benefit of generating revenues, which could be used to finance transmission system improvements, pay startup costs of generators, or defray other costs of system managers, in much the way that system charges and transmission tariffs do in current systems. The extraction of tax revenues will have obvious implications for the profitability of the industry, and for the level of investment 
that it can attract. Price and quantity constraints typically occur at peak loads and times of system stress, which are precisely the times that are crucial for collecting the revenues needed to finance large-scale capital investment required to serve those peak loads efficiently. A tax mechanism may be an effective tool for balancing efficiency and equity while maintaining system stability when the system is constrained. 


\title{
Chapter 3
}

\section{Efficient pricing of a bundled product of both real and reactive power}

\begin{abstract}
This paper examines a price mechanism with one price assigned for each level of bundled real and reactive power. Equilibrium allocation under this pricing approach raises system efficiency via better allocation of the reactive power reserves, neglected in the traditional pricing approach. Pricing reactive power should be considered in the bundle with real power since its cost is highly dependent on real power output. Equilibrium allocation of the bundled pricing was simulated on a simple 3-bus system power auction and compared with free reactive power optimal power flow solution. The efficiency of pricing approach is shown in the general case, and tested on the 30-bus IEEE network with piecewise linear cost functions of the generators.
\end{abstract}




\subsection{Introduction}

An efficient transmission network plays a crucial role in growing power markets around the world. In the last five years generating capacity grew rapidly; however, transmission investment has been declining for many years (US. Department of Energy 2003). Many countries have already adopted competitive market programs where an Independent System Operator (ISO) or Regional Transmission Organization (RTO) is responsible for scheduling and dispatching generators on regional networks, implementing a market-based mechanism for allocating scarce transmission capacity Joskow (2003).

In this paper we analyzed pricing mechanism where certain price is assigned for each level of real and reactive power. With both goods priced market forces stimulate efficient production of real and reactive power. Reactive power is an important component of generator's output. Its efficient procurement is important to control voltage stability and line congestion of the power network.

The direct current (DC) system model is a common approximation for estimating spot market prices under a constrained network. The DC load model is insufficient since it ignores reactive power effects on the production of real power, line congestion and voltage constraints. Therefore, a full $\mathrm{AC}$ model is required to design price mechanism for the bundle of real and reactive power.

Hogan (1993) created a separate price mechanism for reactive power in order to stimulate its production with a purpose of satisfying voltage constraints. Later, Kahn and Baldick (1994) demonstrated that although Hogan's pricing example for reactive power yielded a Pareto improving (more efficient) dispatch, it was not a solution of the formal optimal power flow problem.

After 1994, the theoretical discussion of reactive power pricing shifted into the engineering literature, where it focused on how marginal reactive power should be determined and priced. Hao (1997, 2003) explored the technical and economic issues of determining reactive power structures, and designed a practical solution for managing reactive power services. In his work he looked at the cost-benefit analysis of the reactive power procurement, without considering market incentives. Singh (1999) discussed auction design for ancillary services. 
Much of the engineering research centers on the technical side of the load flow solution algorithm. Weber (1998) modified standard optimal power flow (OPF) analysis to simulate real and reactive power prices. Gil (2000) proposed a theoretical approach of marginal cost pricing for reactive services. Alvarado (1996) suggested marginal cost pricing for dynamic reactive power. These studies emphasize the important role of reactive power in the efficient production and distribution of electricity. Unfortunately, they do not take into consideration market forces that would actually motivate generators to produce reactive power.

They conclude first, that a DC approximation is not sufficient to mimic power flows in a congested network; and second, that reactive power output itself is costly and creates network congestion. What is missing in this debate is a discussion of pricing and bargaining strategy in reactive power markets, similar to work done by economists (Berry and Hobbs 1999) on real power markets using DC approximation.

This paper represents a first step in filling this gap. We present an alternative pricing mechanism where two distinct prices are introduced but the prices of real and reactive power are merged in one bid. While formulating their bids generators evaluate the overall profit they expect to obtain from production. In addition, separating real and reactive power bids increases uncertainty and may decrease market efficiency, since the optimal reactive power bid is extremely volatile, and depends on real power output.

The next section presents a simple three bus network OPF solution is presented as a starting point. It is shown that when reactive power costs are neglected, the OPF solution tends to allocate too much of the reactive power requirement to generators located close to the load. Part 3 explains how reactive power costs are related to the cost of real power, and demonstrates efficiency gain when reactive power cost are taken into consideration. The following two parts introduce a bundled locational marginal pricing method and the intuition behind it. Moreover, 30-bus IEEE network model with piecewise linear costs of generators was used to demonstrate benefits of bundled pricing approach. 


\subsection{Power Network Model}

In this section optimal power flow is analyzed for the increasing demand for the reactive power, keeping demand for the real power constant. For each demand level, OPF that neglects cost of reactive power is compared with the full OPF minimizing costs of both real and reactive power. A small 3-bus triangular AC network example, in which there are two generators and a load connected by transmission lines (see Figure 3.1) is analyzed. The load on bus 3 is satisfied by two generators, so that total costs of production are minimized. With two generators involved it is easy to see changes in the output due to the load change.

Numerical parameters of the transmission lines and generators are given in the Appendix A. Loadflow in Figure 3.1 represent economic dispatch of the generators, neglecting reactive power costs. That is, in order to satisfy the load (1500 MW; $300 \mathrm{MVAr}^{1}$ in this example) in the cheapest possible way, the first generator (G1) has to produce 847.1 MW of real and 8.1 MVAr of reactive power, while the second generator (G2) has to produce the remaining 721.6 MW and 371.1 MVAr. The solution was found by solving a formal non-linear cost minimization subject to transmission, voltage and generation constraints (Appendix 3-A).

This cost minimizing approach is referred to as the Social Planner Solution or alternatively in the power economics literature (e.g. Wilson, 2002) as a Regulated Market Equilibrium. No prices were used to calculate the efficient allocation (Table 3.1).

A competitive market is another way to obtain the same efficient allocation by dispatching generators via a price mechanism. Competition in the power market is organized in the form of an auction, where cheaper generators presumably underbid more expensive generators. When competition eliminates expensive (inefficient) producers, power is produced efficiently (i.e. at the lowest possible cost). Hogan (1993) designed a nodal price mechanism allowing to reach efficiency via market competition with respect to both real and reactive power. When reactive power can be produced at no cost, nodal prices set equal to marginal cost in the competitive market will result

\footnotetext{
${ }^{1}$ megavolt ampere reactive, sometimes denoted as MVar
} 


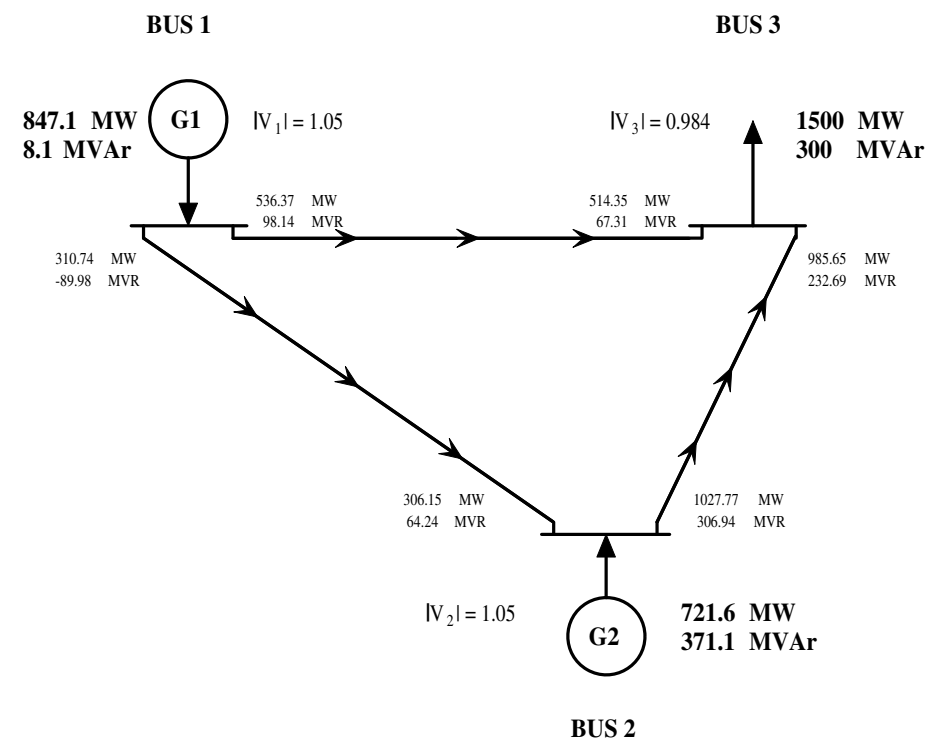

Figure 3.1: Triangular Network OPF example

in an efficient allocation. Therefore, nodal prices allow a generator to outbid its competitors when its "delivered-power" is cheaper. Locational marginal cost prices (LMPs) provide fair competition among generators and ultimately yield efficient dispatch. Under this approach, reactive power is supposed to be a free good when production is adjusted in such a way as to minimize real power losses such that, voltage constraints and line congestion are not violated.

Table 3.1 compares two sets of OPF solutions for the same demand of electricity. In one case reactive power costs are neglected, while in the other case OPF solution minimizes costs of both real and reactive power. Lower part of the table shows differences in the production schedule of each generator after efficient redispatch. For example, -1.52 means that generator 1 has to produce 1.52 MW more when reactive power costs are considered in minimization problem.

Production output differs a lot with increasing reactive power requirements. When demand for reactive power jumps to $700 \mathrm{MVAr}$, the OPF solution yields $\$ 110$ of savings due to more efficient reactive power redispatch. A larger share of reactive power can be produced cheaper by generator 1 , saving costs of the more expensive generator 2. Dollar savings are progressing quickly along with reactive power requirements. With increasing marginal production costs each additional production 
Table 3.1: OPF distortions when costs of reactive power are neglected

\begin{tabular}{|c|c|c|c|c|c|c|c|c|c|}
\hline \multirow{2}{*}{\multicolumn{2}{|c|}{ Demand }} & \multicolumn{4}{|c|}{ Free Reactive Power } & \multicolumn{4}{|c|}{ Costly Reactive Power } \\
\hline & & \multicolumn{2}{|c|}{ Generator 1} & \multicolumn{2}{|c|}{ Generator 2} & \multicolumn{2}{|c|}{ Generator 1} & \multicolumn{2}{|c|}{ Generator 2} \\
\hline MW & MVAr & MW & MVAr & MW & MVAr & MW & MVAr & MW & MVAr \\
\hline 1500 & 200 & 846.03 & -18.48 & 720.38 & 290.87 & 847.55 & 69.69 & 719.59 & 206.65 \\
\hline 1500 & 300 & 847.11 & 8.15 & 721.62 & 371.18 & 845.8 & 97.08 & 723.61 & 286.06 \\
\hline 1500 & 500 & 850.33 & 62.77 & 725.1 & 536.11 & 851.72 & 330.78 & 727.63 & 287.4 \\
\hline 1500 & 700 & 855.1 & 119.39 & 730.03 & 707.37 & 858.58 & 417.6 & 731.31 & 437.55 \\
\hline \multicolumn{6}{|c|}{ hange in output due to efficient pricing } & \multicolumn{2}{|c|}{$\$$ savings } & & \\
\hline 1500 & 200 & -1.52 & -88.17 & 0.79 & 84.22 & \multicolumn{2}{|c|}{48.3} & & \\
\hline 1500 & 300 & 1.31 & -88.93 & -1.99 & 85.12 & \multicolumn{2}{|c|}{59.4} & & \\
\hline 1500 & 500 & -1.39 & -268.01 & -2.53 & 248.71 & \multicolumn{2}{|c|}{87.5} & & \\
\hline 1500 & 700 & -3.48 & -298.21 & -1.28 & 269.82 & \multicolumn{2}{|c|}{110.1} & & \\
\hline
\end{tabular}

unit yields noticable increase in savings, even though actual costs of reactive power are relatively low.

\subsection{Costs of Reactive Power}

Unlike real power reactive power is usually cheap to produce within a certain range. There are three major sources of reactive power production: capacitor banks, synchronous condensers, and generators. This paper focuses on the reactive power share coming from moving machines such as generators and synchronous condensers for which reactive power capacity is proportional to active power output Hao (2003). That is, a certain amount of reactive power can be produced by generators ${ }^{2}$ at no cost; otherwise reactive power is produced by synchronous machine at the expense of real power. Capacitor banks and other static machines are slow-respond reactive power generators. In the scope of this paper only fast responding synchronous generators are considered.

Reactive power is usually generated close to the load, since it can not be transmitted efficiently over a long distance Joskow (2003). The example in Figure 3.1 illustrates this point, as most of the reactive power is produced by generator 2 , which is located closer to the load.

\footnotetext{
${ }^{2}$ According to NERC (2004) Planning Standards guideline, reactive capabilities with 0.95 leading and 0.9 lagging power factors should be available at no cost
} 
A problem arises when a substantial amount of reactive power is assigned to a single generator. Table 3.1 demonstrates OPF dispatch as reactive power demand increases. When load demands $1500 \mathrm{MW}$ and $700 \mathrm{MVAr}$, the existing nodal pricing mechanism (as well as OPF) will require the second generator to produce 730.03 MW and 707.37 MVAr. However, under the normal requirements only about 240 MVAr can be produced at no $\operatorname{cost}\left(\frac{730}{\sqrt{730^{2}+240^{2}}} \approx 0.95\right)$. The remaining share of the reactive power is going to be produced by a synchronous machine consuming approximately 19 MW of real power Kirby (1997), because the cost of reactive power is not accounted for by the LMP.

Many papers in the engineering literature, such as Gil (2000), Weber (1998), and Lamont (1998), developed methodologies and solution simulation methods to account for the costs of reactive power. For purposes of this paper, the MatPower OPF solver was used. Reactive power is considered to be free within the normal reactive requirements set by NERC (0.95 leading and 0.9 lagging power factor). Otherwise, a synchronous machine will consume real power equal to about $3 \%$ of the machines reactive-power rating. Mathematically, the cost of reactive power beyond normal rate can be approximated as the extra cost of the real power, required to generate it.

$$
\operatorname{Cost}(P, Q)=\operatorname{Cost}\left(P+0.03\left(Q-Q^{0}\right)\right)
$$

where

$P$ - demand for real power;

$Q$ - demand for the reactive power;

$Q^{0}-$ reactive power produced by generator at no cost.

\section{SO's Objective Function}

In the most general setup the SO is minimizing production cost of both real and reactive power by solving constrained minimization problem: 


$$
\begin{aligned}
\min _{\{P, Q\}} & \sum_{i=1}^{n} C_{i}\left(P_{i}, Q_{i}\left(P_{i}\right)\right) \\
\text { s.t. } & \sum_{i=1}^{n} P_{i}-P^{\operatorname{loss}}\left(P_{2}, \ldots P_{n}, Q_{2}\left(P_{2}\right), \ldots Q_{n}\left(P_{n}\right)\right)=P_{D} \\
& \sum_{i=1}^{n} Q_{i}\left(P_{i}\right)-Q^{\operatorname{loss}}\left(P_{2}, \ldots P_{n}, Q_{2}\left(P_{2}\right), \ldots Q_{n}\left(P_{n}\right)\right)=Q_{D}
\end{aligned}
$$

subject to voltage, transmission, capacity etc. constraints.

Solution of this problem requires marginal rate of substitution (=ratio of marginal costs between real and reactive power) to be equal among the generators.

$$
M R S_{i}=\frac{C_{i Q_{i}}}{C_{i P_{i}}}=M R S_{j}=\frac{C_{j Q_{j}}}{C_{j P_{j}}} \quad \forall i \neq j
$$

In a simpler setup reactive power costs are not considered. Reactive power is produced in order to minimize costs of real power and satisfy voltage constraint. It reduces to:

$$
\begin{array}{ll}
\min _{\{P\}} & \sum_{i=1}^{n} C_{i}\left(P_{i}\right) \\
\text { s.t. } & \sum_{i=1}^{n} P_{i}-P^{\operatorname{loss}}\left(P_{2}, \ldots P_{n}, Q_{2}\left(P_{2}\right), \ldots Q_{n}\left(P_{n}\right)\right)=P_{D}
\end{array}
$$

subject to voltage, transmission, capacity etc. constraints.

Solution of this problem requires equality of marginal costs among the generators.

$$
C^{\prime}\left(P_{i}\right)=C^{\prime}\left(P_{j}\right) \quad \forall i \neq j
$$

When costs of reactive power are taken into consideration, the OPF solution yields a more efficient distribution of reactive output and hence a more efficient system. (Efficiency is discussed in the section 3.4). Designing a self enforcing price mechanism would help to take into consideration costs that generators have when they need to produce reactive power as well as to stimulate competition and more efficient investment in reactive reserves. At present, no market is deployed for reactive power, meaning that generators have no incentive to produce reactive power unless ordered to do so by the system operator (SO). 
The opportunity cost of reactive power production by a given generator depends strongly on the amount of real power. For example, cost function of a generator (Figure 3.1) implies that it can produce 240 MVAr at virtually no cost when the generator is producing $730 \mathrm{MW}$ of real power, or it can be generated by the synchronous condenser that consumes $7.2 \mathrm{MW}$ of real power when the generator is idle. Since overall generation costs depend on the bundle of real and reactive power, compensation mechanism that pays only for the real power output is clearly insufficient. Graphically, the cost function can be presented as three dimensional surface, with cost level characterized by two coordinates MW and MVAr (see Figure 3.2).
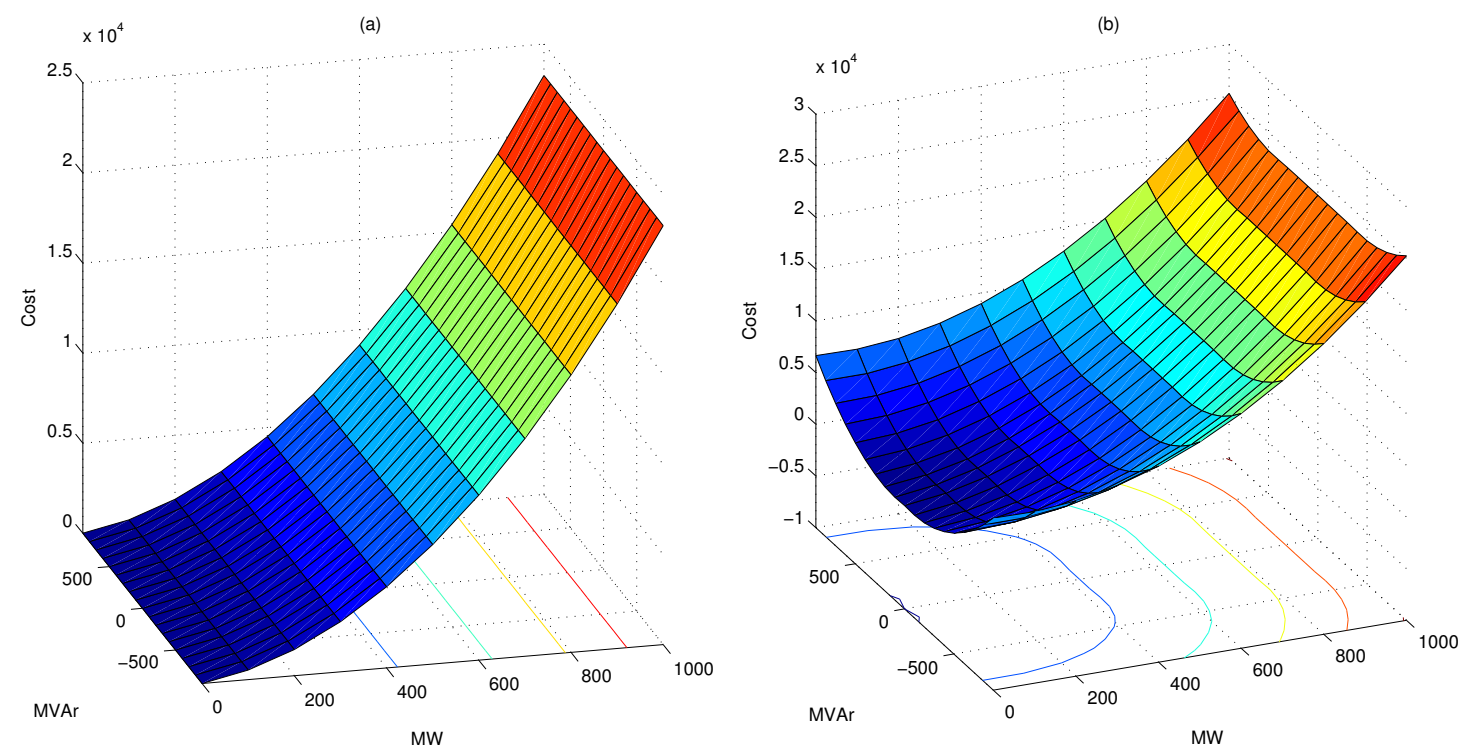

Figure 3.2: Cost surface example for (a) free reactive power and (b) costly reactive power

When reactive power is free (Figure 3.2.(a)) the cost surface is flat. More realistically, reactive procurement outside the range of 0.95 leading and 0.9 lagging power factors ${ }^{3}$ should be produced by the synchronous condenser at the expense of real power Figure 3.2 (b). The contour projection shows reactive capability curves or isocost curves. They are flat in the regions where reactive power is free.

It is assumed that cost of reactive power can be counted in the model as the costs of the additional

\footnotetext{
${ }^{3}$ power factor $=\frac{M W}{\sqrt{M W^{2}+M V A r^{2}}} ;$ leading implies $M V A r>0$, lagging $M V A r<0$.
} 
real power required to produce it. Therefore, the marginal cost of reactive power is determined as the additional cost of producing an extra unit of reactive power, while real power output remains unchanged.

Assume that power is sold in a reasonably competitive market such as $\operatorname{PJM}(2005)$. With many generators on the power market and a system operator enforcing non-cooperative behavior of the generators, competition among its market participants would assure that generators bid their marginal costs. In case of competitive markets for joint goods production, the price for each good is equal to its marginal cost. With joint production, the producer must consider both prices at the same time. Mathematically, the marginal cost of reactive power is calculated as a the first partial derivative of the cost function with respect to reactive power, holding real power output constant. Hence, two prices form a bundle in the sense that both prices have to be cleared at the market simultaneously. It is is important to assign distinct prices to the bundle of real and reactive, since both goods are produced simultaneously and can not be stored separately. Marginal cost of reactive power depends on the quantity of real power output. Therefore, the price of real and reactive power will depend on the production bundle of both goods. In fact cost of real power does not depend on the reactive power output, however reactive power cost is dependent on the real power output.

\subsection{Microeconomic Foundations of the Bundled Pric- ing}

In order to understand the benefits of pricing reactive power it is important to compare it with the traditional pricing mechanism. Figure 3.3 illustrates isocost curves of a generator $i$, which are contour projections of the 3 -dimensional cost surface of the Figure $3.2 \mathrm{~b}$. The flat part of the isocost curve represents the region of costless reactive power. The two dotted lines from the origin mark the border of that region for every possible isocost.

Let $U$ be an indifference curve of the system operator, defined to be the isocost curve for the rest 
of the system to satisfy the load. Let $C(\bar{P}, \bar{Q})$ be a total cost of the power that has to be produced in order to satisfy load demand. Then,

$C(\bar{P}, \bar{Q})=C_{i}\left(P_{i}, Q_{i}\right)+C_{-i}\left(\bar{P}, \bar{Q}, P_{i}, Q_{i}\right)$

Total cost of power is a sum of costs that generator $i$ incurs to produce a bundle $\left(P_{i}, Q_{i}\right)$ and cost of of remaining power that has to be produced by generators other than $i$. Cost of remaining power depends on the system demand $(\bar{P}, \bar{Q})$ and contribution of the generator $i$.

SO's utility $U=C_{-i}\left(\bar{P}, \bar{Q}, P_{i}, Q_{i}\right)$ represents overall minimized cost of the power produced by other generators in the network, except generator $i$. Hence, it is an isocost curve that minimizes system costs excluding the bundle $P_{i}$ and $Q_{i}$. Nevertheless, we will call it "utility" to avoid confusion with isocost curve of generator $i$.

A hyperbolic shape implies that the SO prefers average production bundle of real and reactive over extreme one (only real or only reactive power). Point A on the Figure 3.3 demonstrates a tangency point between generator $i$ isocost and utility level $\bar{U}$. Graphically, one may see that point A represents lowest possible costs for the generator $i$ to achieve utility level $U$. Point $A^{\prime}$ represents another solution, were cost minimization of all the remaining system yields utility level $U^{\prime}$. A line connecting tangency points is a contract curve. Assume that point $A$ minimizes overall system costs. Then, point $A$ represents optimal production bundle of the real and reactive power that minimizes cost of electricity in the network.

The slope of an isocost curve corresponds to the marginal rate of substitution between cost of real and reactive power. The marginal rate of substitution is equal to the ratio of marginal costs between reactive and real power and thus represent the price ratio between those two goods in a competitive markets.

$$
\left|M R S_{P Q}\right|=\frac{M C_{Q}}{M C_{P}}=\frac{\text { Price of } \mathrm{Q}}{\text { Price of } \mathrm{P}}
$$

Hence, when both real and reactive power are sold at the price equal to marginal cost, a generator 


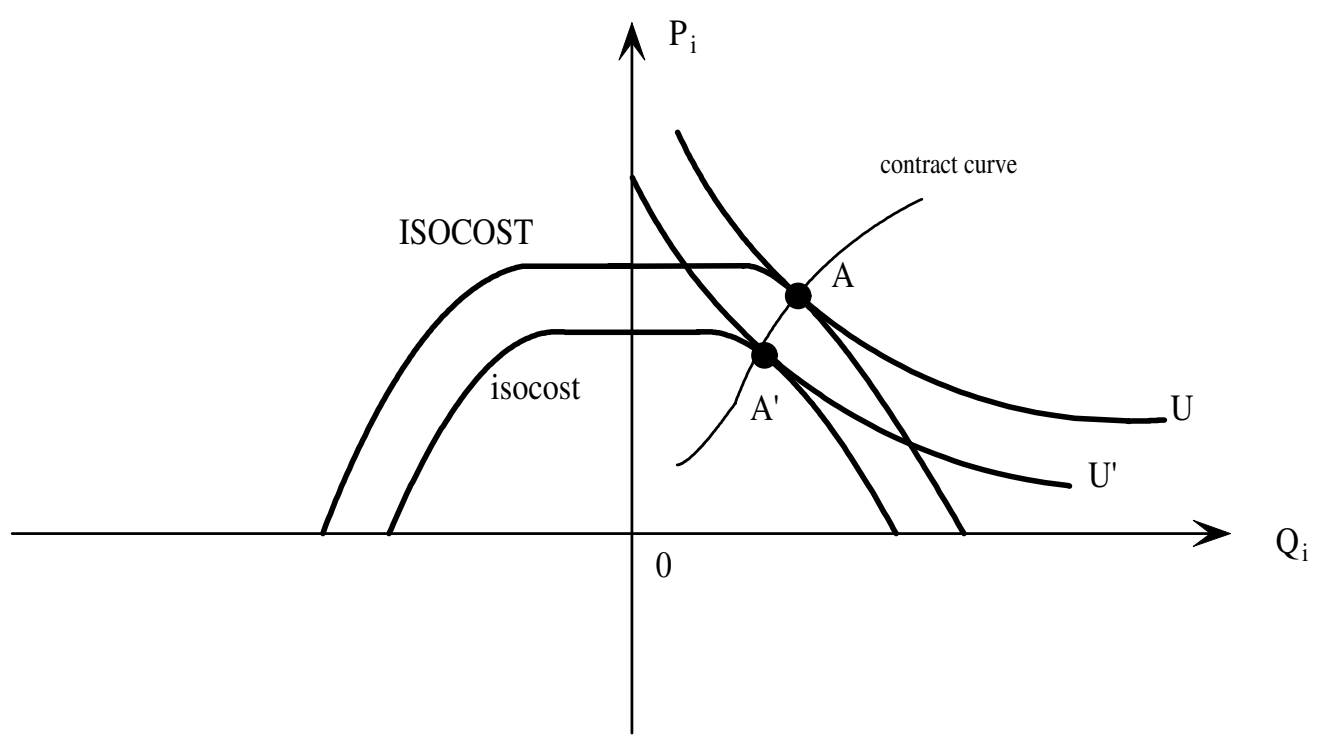

Figure 3.3: Economics of Competitive Prices for the Bundle of Real and Reactive Power

will produce an optimal bundle of real and reactive power (point $A$ ) that satisfies utility level of the $\mathrm{SO}$ at the lowest possible cost.

Unfortunately, PJM and other ISO's currently provide competitive market prices only for real power. Reactive power is treated as a production constraint, determined without consideration of cost. Its limits are considered to be feasible independently from real power output. New isocosts are parallel horizontal lines constrained by limits of reactive power output $\left(Q_{\min }\right.$ and $\left.Q_{\max }\right)$. Both types of isocosts are shown in the Figure 3.4.

At the same time generators located further away from the load might have no distortion at all. Long-distance transmission of reactive power is expensive for the system, which makes SO's utility function U-shaped (see Figure 3.4). Then, tangency between generator's isocost and SO's utility occurs at point $A$ on the flat part of the generator's isocost curve. Slope at $A$ is equal to zero,

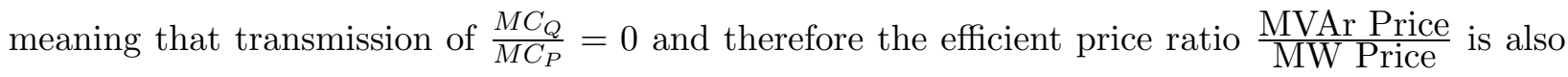
zero. Thus, reactive power should be produced within free range only when its price is equal to zero. Because of this, pricing reactive power will have little affect on a generator located far away from the load, but a strong effect on the generators located near the load. 


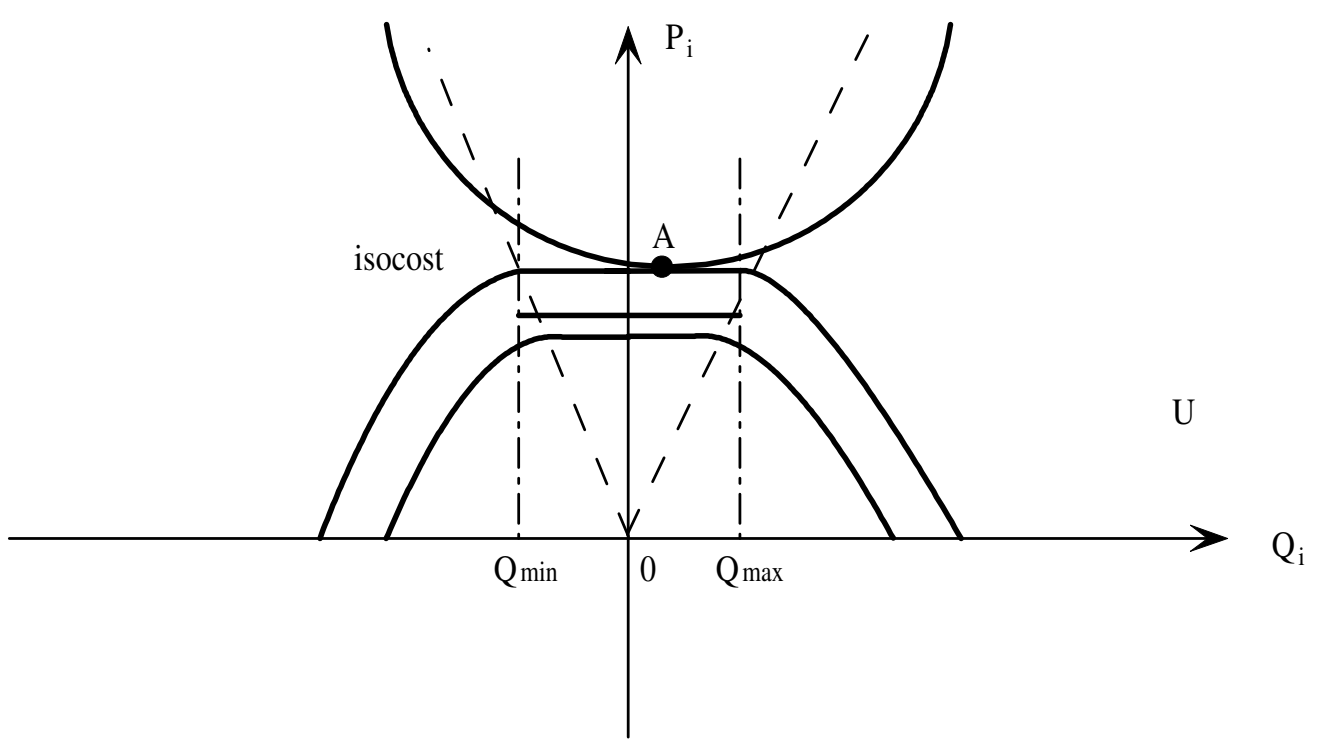

Figure 3.4: Efficient allocation when reactive power price is equal to zero

Thus, pricing reactive power should have a long-run affect on encouraging efficient construction of small generators near load centers.

\section{Market inefficiency caused by absence of reactive power pricing.}

When reactive power has to be produced outside free range but it is not priced - two outcomes are possible.

1) generator is assigned to produce reactive power without compensation. For example production bundle at point $\mathrm{D}$, figure 5 implies that reactive power is costly to produce. With no reactive compensation generator $i$ will incur losses, while producing reactive power.

2) reactive power is going to be produced below generator's capacity. Production bundle at point C, Figure 3.5 is feasible for the generator $i$, however, it remains outside $\left(Q_{\min }, Q_{\max }\right)$ range and thus can not be assigned by the system operator. 


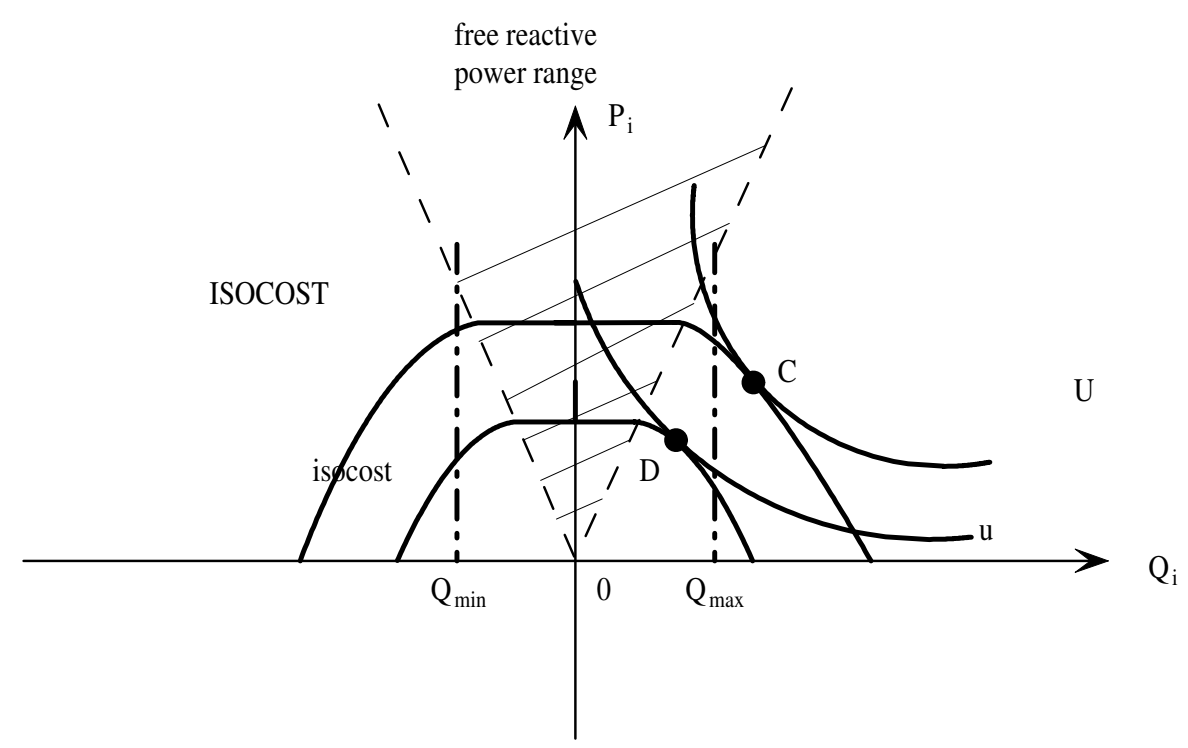

Figure 3.5: Problems of accounting reactive power when it is produced outside free range

\subsection{Numerical simulations of bundled pricing on 30- bus IEEE test network}

In this section we have examined benefits of pricing the reactive power simulated on the IEEE 30-bus power network. There are 6 generators with piecewise linear cost functions that provide power for the 24 load buses of the network (see Appendix 2-C for power flow system diagram).

First, OPF solution minimized production costs of real power only. Reactive power is considered as an additional constraint that can be produced at no costs to generators within specified limits $\left(Q_{\min }, Q_{\max }\right)$. When reactive power costs are neglected, SO operator assigns reactive power schedule to the generators in the system, so that real power losses are minimized. Basically, the SO will assign reactive production level based on generator's capacity, considering costless reactive power within production limits. Reactive power does not "travel" far and thus it is usually produced by the expensive generators located near the load. As a result expensive units might produce a lot of reactive power while real power is delivered by cheaper generators located further from the load. Reactive power can be expensive to produce when it is produced alone, but its cost can be 
Table 3.2: OPF power output for 6 generators 30-bus IEEE test network

\begin{tabular}{|c|c|c|c|c|c|c|}
\hline \multirow{2}{*}{} & \multicolumn{3}{|c|}{ OPF with free MVAR } & \multicolumn{3}{c|}{ OPF with costly MVAR } \\
\cline { 2 - 7 } & MW & MVAR & $\begin{array}{c}\text { MVar above } \\
\text { free range }\end{array}$ & MW & MVAR & $\begin{array}{c}\text { MVar above } \\
\text { free range }\end{array}$ \\
\hline 1 & 36.00 & -4.25 & 0 & 36 & 11.26 & 0 \\
\hline 2 & 30.76 & 5.89 & 0 & 24.61 & 10.11 & 2.02 \\
\hline 3 & 36.00 & 40.27 & 28.4 & 36 & 23.54 & 11.7 \\
\hline 4 & 30.21 & 19.79 & 9.7 & 32.39 & 12.34 & 1.69 \\
\hline 5 & 22.55 & 7.54 & 0.1 & 26.72 & 7.41 & 0 \\
\hline 6 & 36.00 & 34.79 & 22.9 & 36 & 37.89 & 26.06 \\
\hline
\end{tabular}

substantially reduced or eliminated entirely when it is produced in a bundle with an appropriate amount of real power.

Table 3.2 demonstrates efficient production dispatch for two markets, one with free reactive power, another one with costly reactive power. Lefthandside of the Table 3.2 demonstrate efficient production dispatch that minimizes costs of real power only. Righthandside shows efficient dispatch that minimizes costs of both real and reactive power. The lefthandside solution is equivalent to the competitive market outcome were only real power has its price (Hogan 1992). The righthandside solution is equivalent to competitive market outcome where both real and reactive power are sold (Hogan 1993).

When costs of reactive power are neglected, optimal dispatch minimizes losses of the expensive real power. Generator 1 and 2 located "electrically far" from the load, thus they produce a lot of real power and very little of reactive power. Reactive power is produced within free range, thus its price is equal to zero for both generators 1 and 2 (see Figure 3.4). Other generators incur additional costs while producing reactive power.

It makes procurement of the reactive power highly undesirable by generators $3,4,5$ and 6 . They have to produce reactive power without being paid, while generators 1 and 2 free ride. Indeed, without proper compensation incentives reactive power becomes a good that no one is willing to produce. Figure 3.5, point D refers to the situation when generators are not compensated for the reactive power output. 
When reactive power is priced generators are compensated for their reactive power output. In this case OPF solution minimizes costs of both real and reactive power. Reactive power can be produced at $5 \%$ of real power costs when it is produced above free range. That is why, pricing reactive power does not shift real power schedule a lot (see Table 3.2). This fact explains a lot why reactive power is neglected at the modern power auction, and its costs are relatively small while estimating overall system efficiency.

At the same time pricing reactive power substantially changes reactive power schedule among the generators. For example, generator 6 is "specializing" in reactive power power procurement. Naturally, with proper compensation mechanism, generator 6 would be interested in expanding its reactive capacity, since this generator has a relative advantage in the reactive power procurement. When production of the reactive power is profitable generators will try to expand it output above nominal limits.

However, for smaller generators specializing in the reactive power procurement cost of reactive power will vary depending on its proportion with real power. Therefore, having a bundled pricing approach is required for the bundled output of two goods. It implies that opportunity costs of reactive power are higher than real power output for the generator 6 . Naturally, generator 6 would be interested in expanding its reactive reserves only in case of proper compensation for the reactive power. When production of the reactive power is profitable generators will try to expand it output above nominal limits.

Generators 3 and 4 procure a lot less reactive power when it is priced. Instead more reactive power is scheduled to be produced by other generators, capable to produce reactive power cheaper (generators 1 and 2).

Figure 3.3, illustrates optimal dispatch for the generators 2, 3, 4 and 6 . All those generators produce reactive power above free range. Figure 3.4, illustrates production schedule of generators 1 and 5. Both generators produce reactive power within free limits, implying zero price for the reactive power. 


\subsection{Conclusions}

In this paper a pricing mechanism for real and reactive power was proposed. The offer for reactive power is generated as a function of real power prices. One price is imposed for certain level of real and reactive power. As a result, the supply function of a generator becomes a surface in threedimensional space. The efficiency gain for the bundled pricing over traditional real power LMP is equivalent to the gain for using an OPF solution that with reactive power cost, over the OPF with free reactive power. That is the bundled pricing scheme allows more efficient distribution of reactive power resources and creates autonomous competitive market mechanism for the reactive power. In particular it will positively influence the generators located close to the load. These generators usually produce relatively more reactive power without proper compensation. It makes procurement of the reactive power highly undesirable by market participants. Reactive power in a sense becomes a public good that no one is willing to produce. Generators will either have to produce reactive power at loss, or include it in the cost of real power.

At the same time generators located further, might not be affected by this pricing mechanism. When reactive power is produced within free range, its competitive price is equal to zero.

It would be interesting to analyze strategic bidding of generators under the bundled price competition. That is generators acting strategically could withhold their production capacity causing energy prices to increase. In particular competition for reactive power is focused among smaller number of participants located near the load. 


\title{
Chapter 4
}

\section{Mean-Variance Portfolio Analysis of the Locational Value of Generation}

\section{Assets}

\begin{abstract}
This paper addresses the problem of optimal investment in generation based on meanvariance portfolio analysis. It is assumed the investor can freely create a portfolio of shares in generation located on buses of the electrical network. Investors are risk averse, and seek to minimize the variance of the weighted average Locational Marginal Price (LMP) in their portfolio, and to maximize its expected value. I conduct simulations using a standard IEEE 68-bus network that resembles the New York - New England system and calculate LMPs in accordance with the PJM methodology for a fully optimal AC power flow solution. Results indicate that the network topology is a crucial determinant of the investment decision as line congestion makes it difficult to deliver power to certain nodes at system peak load. Determining those nodes is an important task for an investor in generation as well as the transmission system operator.
\end{abstract}




\subsection{Introduction}

The emergence of centralized physical markets in electric power has led to complexities and new opportunities for managing risks in both the operation and finance of power generation facilities. In a typical power markets such as PJM, compensation of generators is based on locational marginal cost prices (LMPs) calculated at each node on the system. The main factor that causes dispersion of the nodal prices of electricity is network congestion, which requires expensive generators to be dispatched before cheaper ones. An important task for the system operator is to identify the locations of chronically congested lines, and to determine the best places to add new generators or transmission system enhancements.

Identifying congested lines requires numerical simulations due to the non-linearity and complexity of the full $\mathrm{AC}$ power flow problem (Bergen 2002). In addition, demand for electricity is a highly stochastic variable that depends on weather, development of industrial units etc. Resulting fluctuations in nodal electricity prices make it hard to estimate the ideal location of additional generators or transmission lines. The non-linear nature of the physical power flows causes price peaks to appear in different places on the network as the load changes. It is even possible for the high price of electricity in one area to be eliminated by a demand increase in another area. Evidence of this can be found in the PJM (2004) data in the form of negative prices. Negative prices imply that an increase in consumption of power can relieve congestion and save production costs.

While planning additional generating units, it is important to consider both the nodal price and its variance. The price of electricity is a highly volatile variable. It can jump from $\$ 30$ per $\mathrm{MW} / \mathrm{h}$ to more than a $\$ 1000$ during peak demand.

Mean-variance portfolio theory developed by Harry Markowitz (1962) is widely used by financial economists to determine the investment portfolios that produce efficient outcomes under various economic conditions. In the framework of investment planning policy it can be used to identify where in the network additional generation capacity should be installed, or alternatively, which buses will be most affected by network congestion as the load increases. 
There have been several academic studies on mean-variance analysis for the deregulated electricity market in both the economics and the engineering literatures. Economists usually focus the attention of the investor on the cost of electricity generation. For example, Awerbuch and Berger (2003) look at the value of diversification of investment among various production technologies such as nuclear, fossil fuel, or green power. An efficient generating portfolio minimizes expected costs of electricity for a given risk of fuel cost increase. This approach is useful in the long run (more than a year) since it does not consider line congestion, network topology, and production constraints. Yu (2003) analyzed a spatial mean-variance model, with its spatial nature captured using the correlation of prices in geographically separated markets. Overall, economic literature applies mean-variance to diversify risk on the cost side. Optimal frontier determines investment shares into various production technology. Optimal investment share into each technology provides the lowest expected price for the electricity for given fluctuations in the costs of fuel.

The revenue side of the power market represents nodal price, paid per unit of output at each node. Hogan (1992) showed that the LMP pricing mechanism should provide proper incentives for efficient distribution of power production among generators. LMP's volatility depend a great deal on the network congestion. The volatility level of the nodal prices exceeds fluctuation of the fuel costs a lot.

In contrast, the engineering literature emphasizes the importance of full AC load flow analysis, subject to network topology, voltage constraints, transmission losses, etc, and none emphasize the use of financial tools in investment policy.

Denton(2003) suggests construction of an efficient frontier to determine intermediate term market risk (from one month to a year).

The mean-variance approach helps to estimate nodes with the highest expected LMP taking into consideration the correlation among prices at each node. Simulations targeted to determining the most attractive buses for future investment are conducted on the standard IEEE 68-bus test network with generators, high voltage lines, and loads that represent a simplified New York - New 
England power system.

\subsection{Simulation methodology}

The goals of modeling are to simulate a competitive power auction using an electrical engineering network model and then examine correlations among nodal prices and construct the efficient frontier from a financial perspective. The model uses a 16-generator system with 86 transmission lines (see Appendix B) and is a simplified representation of the existing power system in the New York New England area. The following 6 steps represent the simulation algorithm:

1) Simulate a load increase;

2) Calculate the optimal power flow (OPF) for each given load;

3) Determine the LMP at each node for each given load;

4) Calculate the LMP mean and variance-covariance matrix;

5) Estimate the mean-variance efficient frontier;

6) Determine optimal investment shares at each bus for the representative agent.

The first 3 steps represent the "engineering" part of the research. Each simulated load scenario is satisfied in the least expensive way. Production costs are minimized when generators sell power on the competitive market such as PJM power auction. Both cost minimization and nodal prices are calculated for the full AC load flow model following PJM algorithm.

Steps 4, 5 and 6 represent the financial part of the research. A mean-variance frontier is constructed for the nodal prices calculated for the stochastic load increase. The representative agent selects a portfolio on the mean-variance frontier, depending on his risk aversion. That portfolio yields the highest expected nodal prices for the given level of risk. Put in another way, the investor will be interested in adding generators to the buses that pay the most for the power, at lowest possible risk. 
Each of the steps is explained below in detail

\section{Load simulation scenario}

A random walk with drift is used to simulate a $10 \%$ increase in load over the $\mathrm{T}$ simulation periods.

$$
\operatorname{LOAD}_{t}^{i}=\operatorname{LOAD}_{0}^{i}+\alpha_{i} t+\epsilon_{t}
$$

where

$t=1,2 \ldots T$

$\operatorname{LOAD}_{0}^{i}=$ initial load at the $i$.

$\alpha_{i}=\frac{\Delta \mathrm{LOAD}^{i}}{\Delta T}=\frac{0.1 * \mathrm{LOAD}^{i}}{T-1}$ slope of the drift

$\epsilon \sim N\left(0,0.001 * \mathrm{LOAD}^{i}\right)$

Figure 4.1 demonstrates load simulation example for the $2.53 \mathrm{MW}$ load at one of the buses over 30 periods. The straight line represents the trend line without shocks. The load at each bus of the system was simulated independently using the same technique.

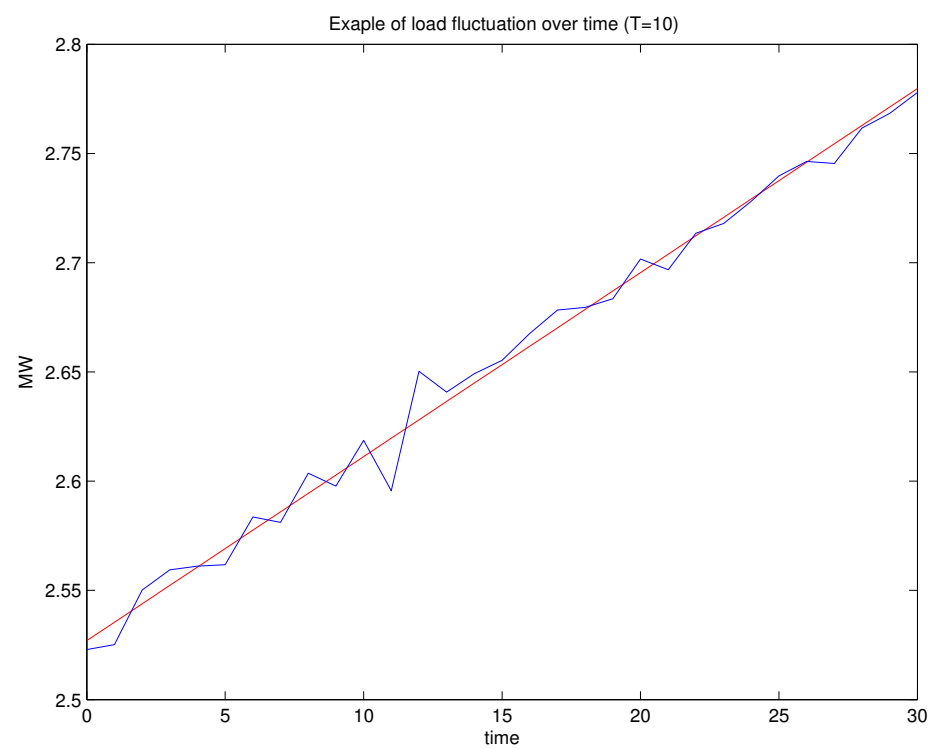

Figure 4.1: Example of load fluctuation over time $(\mathrm{T}=30)$ 


\section{Linear programming OPF and LMP}

For the purposes of this simulation, it is assumed that power is sold competitively on the power auction maintained by PJM. Hogan(1992) shows, that under sufficient competition among generators, a power auction will yield an efficient dispatch. The LMP is the market clearing price at each node of the power network that yields lowest possible cost of generation (efficient solution). In the current paper, the power auction was simulated in reverse order. First, lowest possible generation costs were found (solution of the OPF) and second, nodal prices (LMP) for the efficient allocation were found.

The $\operatorname{PJM}(2004)$ methodology was used to calculate LMP in this paper. This approach takes into account line congestion and the marginal costs of generators but neglects line losses.

The optimal power flow (OPF) was solved for load simulations at each point of time, and LMPs representing the system operator's (SO) willingness to pay per unit of power at each bus were calculated.

\section{Constructing the Efficient Frontier and Finding Optimum Investment Buses}

In classical portfolio theory, maximizing the expected return for a specified level of risk is a standard problem (Markowitz 1952). Simply put, portfolio optimization is the search for a vector of investment portfolio shares that satisfies all constraints and provides minimum total variance with maximum return. There are typically many such vectors, and their risk/return metrics allow construction of the "Efficient Frontier" of this problem space.

The Efficient Frontier approach requires calculating the mean and variance of return for each portfolio. In our case, the portfolio consists of ownership shares of nodes on the system. We calculate returns at each node from the LMP. Mean LMP at each bus was calculated by taking the arithmetic average of its LMP over time. Calculating LMP variance required construction of the variance-covariance matrix between LMPs. 
Table 4.1: An example where portfolio of two assets are preferred to the higher return lower risk asset

\begin{tabular}{|c|c|c|c|c|c|}
\hline \multicolumn{4}{|c|}{ Correlation Table } & & \\
\hline$\rho$ & Asset 1 & Asset 2 & Asset 3 & $\mu$ & $\sigma^{2}$ \\
\hline Asset 1 & 1 & -1 & 0 & 0 & 49 \\
\hline Asset 2 & -1 & 1 & 0 & 2 & 9 \\
\hline Asset 3 & 0 & 0 & 1 & 10.5 & 6.25 \\
\hline
\end{tabular}

\section{Portfolio Selection}

The efficient frontier for the investor represents the set of portfolios that have highest expected LMP for each given variance. Choice of a particular portfolio on the frontier depends on investor's degree of risk aversion. This level of aversion to risk can be characterized by defining the investor's indifference curve. Constant absolute risk aversion (CARA) preferences $U=-e^{-w \gamma}$ are typically used in financial theory (Grossman and Stiglitz 1980). $U$ is investor utility and $w$ is wealth. The parameter $\gamma$ represents investor's risk aversion. Typical risk aversion coefficients range between 2.0 and 8.00, with the higher number representing less tolerance to risk. The same CARA utility function was used to simulate the representative investor in the power network. Note, that $V=$ $E(w)-\frac{\gamma}{2} \operatorname{Var}(w)$ captures the investor's trade-off between risk and return. Also, maximizing $V$ is equivalent to maximizing $U$ (Grossman and Stiglitz 1980).

Below we provide an example that emphasizes importance of the mean-variance analysis. Each asset is characterized by its expected return $\mu$, risk of the return $\sigma^{2}$ and its correlation with another assets. These data are summarized in the Table 4.1.

At first sight it seems that an investor should spend all his money purchasing asset 3 . This asset has highest expected return and lower variance. However, it is possible to design a portfolio investment from the asset 1 and 2, so that the investor will prefer it over spending all his money on asset 3 . Assets 1 and 2 are perfectly negatively correlated, but asset 3 is not correlated with any other asset $\rho_{12}=-1, \rho_{13}=\rho_{23}=0$. Negative correlation between two assets implies that increase in expected return of one asset is followed by a decrease of return in the other. In the scope of this paper, LMP increase in the business area can be followed by LMP decrease in the residential area. Therefore, 
an investor can mitigate portfolio risk by diversifying its investment portfolio among negatively correlated assets.

For example, when the investment dollar is split $(0.3,0.7)$ among asset 1 and asset 2 respectively, expected return of portfolio $E\left(R_{p}\right)=0.3 * 0+0.7 * 2=1.4$, portfolio variance $\operatorname{Var}\left(R_{p}\right)=0.3^{2} *$ $49-2 * 0.3 * 0.7 * 7 * 3+0.7^{2} * 9=0$. It implies that two assets that have high value of risk can be combined in the portfolio with the smaller value of risk. In this particular example, portfolio of the assets 1 and 2 is risk-free. An investor with CARA utility function will prefer this portfolio over the investment everything into asset 3 when his risk aversion parameter $\gamma>2.912^{1}$.

This example demonstrates that for investment planning it is important to consider portfolio of assets, as well as correlation between assets, rather than analyzing prices at the single nodes.

\subsection{Simulation Results}

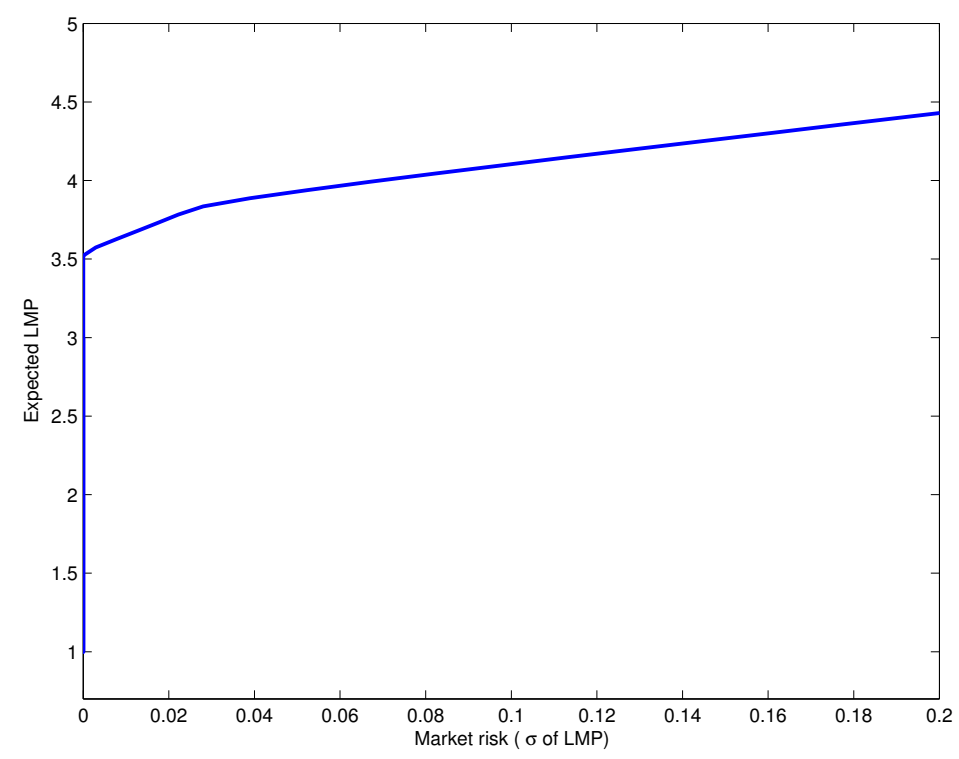

Figure 4.2: Efficient frontier for 68-bus power system

Figure 4.2 demonstrates the outcome of the simulations for the 68-bus New-York New England IEEE

$$
{ }^{1} \text { when } \gamma=2.912 \quad U\left(R_{p}\right)=U(\text { asset } 3)
$$


system. The efficient frontier is calculated for the LMPs using an OPF algorithm in the increasing load scenario (steps 1-5). The highlighted area on the efficient frontier is a set of portfolios that would be chosen by representative investors with risk aversion coefficient in the range from 2 to 8 of the CARA utility function. Those portfolios represent set of buses that will have highest expected LMPs after the anticipated $10 \%$ load increase. In other words, the efficient portfolio identifies nodes that will have the highest average price at each level of price risk for the given load increase. Investment shares for this portfolio can be interpreted as corresponding weights that each node contributes for the expected peaking LMP. In this network, locational prices on buses 3,33 and 65 (see Appendix 3-B) will form highest expected LMP. Basically, the mean-variance technique allows the SO to determine system nodes that will have highest expected price, with the lowest possible variation of that price. Optimal investment shares will determine how much the peaking price at each bus contribute to the overall expected LMP. For example, the optimal investment share is around $99 \%$ in buses 3 and 33. Those buses are located in the congested part of the network. This requires more expensive generators to produce power, which raises the nodal price. Therefore, these buses should be considered for installing additional generation capacity or planing to build additional transmission line.

It is important to mention that the expected peaking price determined in the scope of this paper does not count anticipate withholding production capacity, exercising market power, or any other form of generator gaming. Hence, the predicted peak might be substantially lower than actual price experienced in a real system that is subject to market power manipulation.

\subsection{Adding generators}

The task of the SO is to plan future expansion of the network in such a way that the load increase will cause minimal increase in electricity prices due to network congestion. One way to do so is to install additional generators on the buses with high predicted LMPs. 


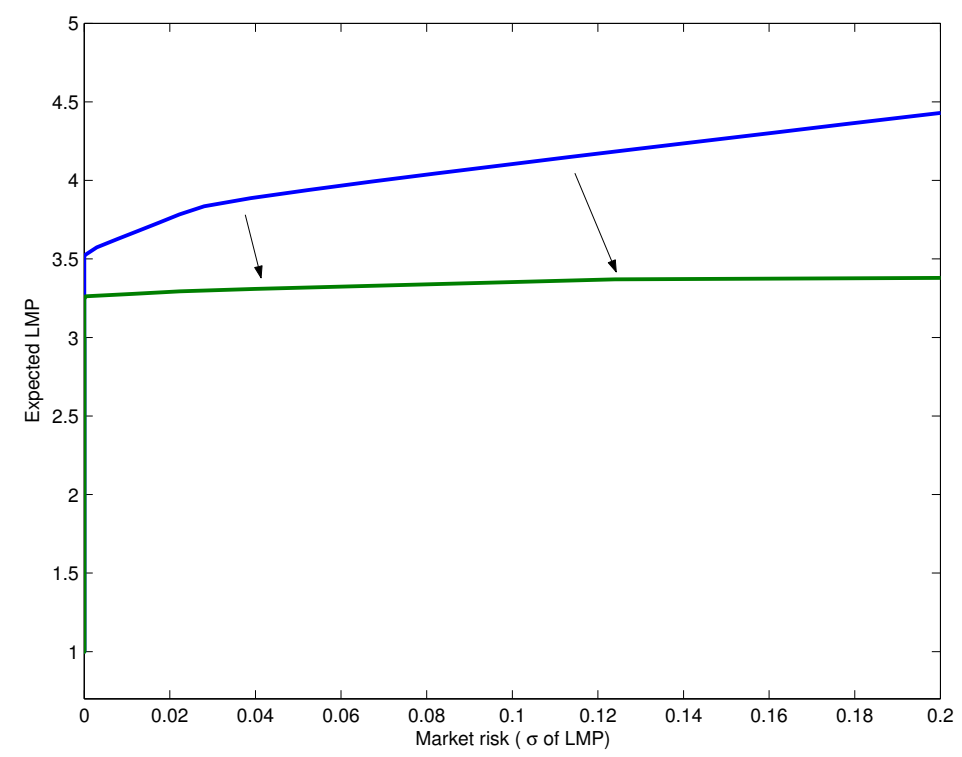

Figure 4.3: Shift of the efficient frontier after adding generators to buses 3 and 33

The effect of adding generators can be measured by constructing the the new mean-variance frontier with the new generation installed and comparing it to the one found with no additional generation. This makes it easy to compare projects of adding generators to the network. When one or more generators are added, the mean-variance curve will be shifted down due to lower prices at each nodes at all time.

These effects were calculated when additional two average generators were added to the bus 3 and 33 and all the simulations steps where done over again. The resulting mean-variance curve together with original one is depicted in the Figure 4.3.

\subsection{Optimal Investment Strategy}

The efficient frontier represents the highest expected price of electricity when load increases. This will maximize the objective function of the investor in generation with the output share negligible to the total output. For example, installing wind generators on buses 3 and 33, will have no influence into the price distribution. Zero fuel costs, but high installation and maintenance costs make a 
wind project sensitive to the expected price paid per unit of output. Therefore, this investment strategy will maximize expected profit of the small power producer.

Some investors will desire lowest possible expected price at each node. In particular, when SO plans to add large generator to the network. The SO's objective is to plan construction of a large scale generator that can satisfy increasing demand, reduce network congestion and thus yield lower electricity prices. A substantial increase in production capacity will cause a shift of the efficient frontier. A downward shift of the efficient frontier serves the SO' interest.

Figure 4.3 represents a set of efficient frontiers achieved by installing a generator at various nodes of the network. Adding a generator to bus 4 produces the almost horizontal frontier located below. First, it implies low expected price of the network. Second, a flat frontier implies the same price for any level of load variation, implying market stability and low congestion. Efficient frontier after adding a generator to the bus 4 is located below the one obtained by adding two generators (at the bus 3 and 33) to the network. It implies that larger capacity can not be injected into the buses 3 and 33 due to network topology, resulting congestion and high prices.

Finally, large scale generation capacity may be sponsored by the profit maximizing firm. Such a firm will want the highest possible location of the efficient frontier. The highest expected LMP after the efficient frontier shift will maximize profit of the company (in the framework of constant marginal costs).

At first sight, it may seem impossible for production costs to fall, while market clearing price rise in a competitive market. A decrease in production costs occurs when a generator whose production cost is lower than that of the most expensive generator on the network. The electricity market a competitive equilibrium yields efficient allocation (power is produced at the lowest possible cost). However, the reward paid per unit of power yields an uneven profit distribution. For example, below is a simple demonstration of the power auction showing this phenomenon:

Table 4.2 represents the basic principle of assigning a nodal price to the generators that do not face network congestion. All the generators have linear cost functions and constant marginal 
Table 4.2: Examples of power auction where decrease in output costs does not change LMP

\begin{tabular}{|l|c|c|c|c|c|c|c|}
\hline \multicolumn{4}{|c|}{ Example 1 } & \multicolumn{4}{|c|}{ Example 2 } \\
\hline & MC & MW & TC & & MC & MW & TC \\
\hline Gen. 1 & $\$ 20$ & idle & $\$ 0$ & Gen. 1 & $\$ 20$ & idle & $\$ 0$ \\
\hline Gen. 2 & $\$ 15$ & 2 & $\$ 30$ & Gen. 2 & $\$ 15$ & 2 & $\$ 30$ \\
\hline Gen. 3 & $\$ 10$ & 5 & $\$ 50$ & Gen. 3 & $\$ 10$ & 5 & $\$ 50$ \\
\hline Gen. 4 & $\$ 10$ & 6 & $\$ 60$ & Gen. 4 & $\$ 5$ & 6 & $\$ 30$ \\
\hline
\end{tabular}

costs (MC). We assume a competitive power auction with all participants bidding their marginal costs. In example 1 generators 3 and 4 are producing at maximum capacity, while generator 2 is producing only 1 unit due to demand constraint. The total costs of production for Example 1 is $0+15+50+60=\$ 125$ and $\$ 15$ is a market clearing price paid to all the generators that produce electricity.

Generator 3 is called marginal generator, since market clearing price is equal to its marginal costs. When production costs of the 4th generator decrease (Case 2), the market clearing price of the auction remains at $\$ 15$. This situation shows that in general decrease in production costs does not neccesary decrease LMP.

When a generator with costs lower than marginal generator is added to the network, overall production costs usually decrease. However, the network congestion caused by adding cheaper generator can yield higher LMP. It happens when the congestion caused by cheaper generation shifts marginal generator. Table 4.3 demonstrates how network constraints can raise the price. A generator 5 is added to the network. New generator is capable to produce at most $1 \mathrm{MW}$ of power $\$ 10$ cheaper than marginal generator 2 . Assume that production of the marginal unit is at its minimal generation level. That is generator 2 has a minimimal operating capacity of $2 \mathrm{MW}$.

Consequently, SO will consider two dispatch options (see Table 4.3):

1) generator 5 is on, generator 2 has to go offline, causing increase of the marginal unit;

2) generator 5 is not allowed to enter, thus generator 2 remains marginal.

The SO will select the first option, since it allows to produce electricity cheaper. Total production 
Table 4.3: Example demonstrating increase in LMP while production costs are decreasing

\begin{tabular}{|l|c|c|l|c|c|c|l|}
\hline \multicolumn{3}{|c|}{$\begin{array}{c}\text { Initial Condition } \\
\text { Option 1 }\end{array}$} & \multicolumn{4}{c|}{$\begin{array}{c}\text { Adding a generator 5 } \\
\text { Option 2 }\end{array}$} \\
\hline & MC & MW & TC & & MC & MW & TC \\
\hline Gen. 1 & $\$ 20$ & idle & $\$ 0$ & Gen. 1 & $\$ 20$ & 1 & $\$ 20$ \\
\hline Gen. 2 & $\$ 15$ & 2 & $\$ 30$ & Gen. 2 & $\$ 15$ & offline & $\$ 0$ \\
\hline Gen. 3 & $\$ 10$ & 5 & $\$ 50$ & Gen. 3 & $\$ 10$ & 5 & $\$ 50$ \\
\hline Gen. 4 & $\$ 10$ & 6 & $\$ 60$ & Gen. 4 & $\$ 10$ & 6 & $\$ 60$ \\
\hline & & & & Gen. 5 & $\$ 5$ & 1 & $\$ 5$ \\
\hline
\end{tabular}

cost of the second option is $\$ 135$, which is $\$ 5$ less than option 1 .

This example shows that higher LMP is followed by the efficiency gain (decrease in the overall costs). Hence, profit maximizing investor will try to allocate production resources in such a way that production expansion will shift marginal generation upwards. That is why, it is possible to have efficient frontier actually moving upwards, while overall production costs go down. The upward shift of the efficient frontier is an empirical evidence of average increase in price while overall production costs does not increase. ${ }^{2}$ High expected LMP represent the investment strategy of the profit maximizing generator. Therefore, an investor in the large power generator will be interested to install generation so that it will result the most upward shift of the efficient frontier (depending on the index of the risk-aversion).

\subsection{Conclusion}

Mean-variance analysis can be used by the system operator and investors to calculate the risk and returns from investments at various nodes in the system with stochastic load fluctuations. This approach takes into consideration both nodal price variance and covariance with the prices on the other nodes. It can be applied to guide investment projects for the intermediate term time span (more than one month but less than a year (Denton 2003)). In this paper, standard IEEE 68 bus

\footnotetext{
${ }^{2}$ the generator added has no start-up and shut-down costs, hence OPF solution after adding the generator will not raise overall production costs
} 


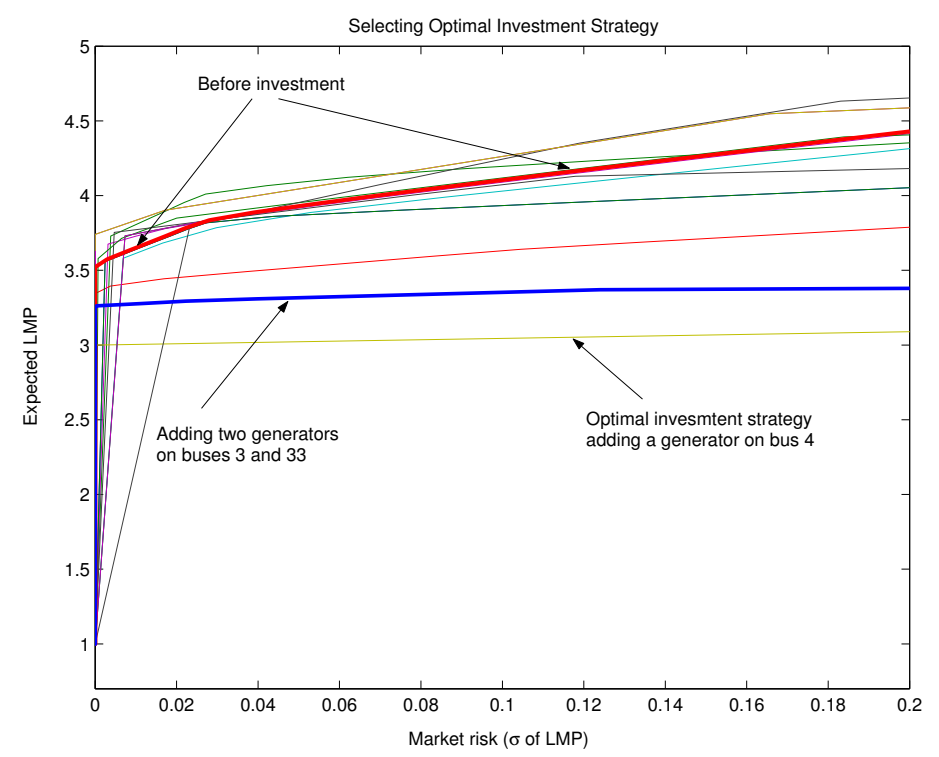

Figure 4.4: efficient frontiers for various investment projects

test system was analyzed. The load was allowed to increase stochastically by $10 \%$. Then, OPF was calculated for the given load fluctuations and LMP were calculated using the PJM calculation methodology. The mean-variance efficient frontier was constructed based on the fluctuations of LMP for the given load increase. A typical representative agent with CARA preferences selects an optimal portfolio based on his or her risk averse index. Buses 3, 33 and 65 are the only buses that form an optimal portfolio of investment in the network for the risk averse index in the range from 2 to 8. Adding additional generation will maximize profit of the generating company, whose output is negligible comparing to the overall system.

When the production capacity of the new entrant is substantial it reduces the network congestion and changes nodal prices of the system. Objective function of the SO is to minimize network congestion and consequently keep nodal prices low. In that case adding a large scale generator to the bus 4 will yield lowest expected price at all nodes. Flat efficient frontier implies low price for any risk level, meaning high network stability. Finally, it will result cheaper electricity for the ultimate consumers.

When the owner of the large generator is responsible for the investment decision making, the most 
upward location frontier will represent his or her investment plan. This will represent production allocation where decrease in production costs are followed with higher electricity prices. 


\section{Chapter 5}

\section{Policy Conclusions and Paths for Further Research}

This dissertation comprises a set of three papers on strategic bidding, pricing and risk management in electricity markets. The second chapter demonstrates how, in a price and quantity constrained electricity market, generators can increase their profits by bidding strategically. The bidding process will not converge (no Nash Equilibrium exists) unless mitigative measures are taken by the system operator. I propose a simple tax mechanism to mitigate strategic bidding. It produces incentivecompatible bids that allow the SO to minimize costs of satisfying the load without knowing actual parameters of the generators cost function. With the imposition of this tax, it is possible to identify the true costs of generation, minimize production costs and extract tax revenues at the same time. Price constraints due to price caps usually occur during the few hours of peak load, which may narrow the applicability of this research. However, these times are particularly important to mitigate market power and for collecting rents needed for financing large-scale capital investment. As with all theoretical work, modeling the tax mechanism and its analysis required a number of simplifications, some of which could affect the conclusions. Therefore, I future research in this area should extend this work in several ways. First, transmission constraints, network topology, and 
other associated constraints that impact dispatch decisions should be considered and simulated in future research. These factors are in particular relevant for the fixed price and quantity markets discussed in the paper. Second, the analysis should be extended to consider strategic behavior under uncertainty. That is, how will the firms' incentives change if they know beforehand that price and quantity will be fixed, but they are uncertain as to the values? Strategic deviation from true costs at peak could hurt generators during off-peak.

In the third chapter I have extended traditional LMP pricing mechanism by designing a bundled pricing approach for real and reactive power. The price mechanism explicitly incorporates the production and cost relationships between the two products. Reactive power is costly to produce in the realistic power system. It accounts for three to five percent of the real power costs when produced by synchronous condensers. Reactive power supply or consumption can create opportunity costs when generators must reduce real power output to supply reactive power.

Prices for both real and reactive power should reflect opportunity costs. That is, for all scarce services, compensation must be received by the suppliers and be paid for by the consumers. Otherwise, market participants must mark up the remaining priced products in hopes of compensation for the loss of complete pricing. Therefore bundled pricing would help to stimulate competition and correct incentives for future investments.

A pricing method that takes both needs into account can provide incentives to ensure that the market produces lower total system costs and provide more opportunities for short-run efficiency gains. Developing software to allow efficient pricing of reactive power in real time could be a barrier to practically implement proposed pricing method. Further research agenda should investigate strategic bidding under imperfect competition, applying bundled pricing approach.

In the fourth chapter I have addressed the problem of optimal investment in generation assets based on mean-variance portfolio analysis. This is a simulation-based study that applies existing financial theory to the electrical network. The optimal portfolio of investments at different nodes in the system is analyzed in terms of locational marginal prices, their fluctuations and correlations. 
Research findings indicate that network topology is a crucial determinant of the investment decision as line congestion complicates power delivery to certain nodes.

In addition, I investigated the ex-ante effects of adding an average size generator to the various locations of the power network. It turned out that adding a generator can shift the efficient frontier either upward and downwards. A downward shift of the efficient frontier implies that by adding a generation expected prices decrease through releasing network congestion. An upward shift of the efficient frontier implies that a reduction in production costs can occur simultaneously with increase in expected prices. It happens when profit maximizing investor will try to allocate production resources in such a way that production expansion will shift marginal generation upwards. Therefore, existing rules of power auction allow gaming of the network in the long run.

An interesting extension should develop investment behavior under cooperative behavior of the generators. So far, I have shown that even in perfectly competitive markets strategic entrance can shift marginal generators. Withholding production capacity is an easier way to do it. These kinds of investigations can bring new insights into our understanding of newly deregulated power markets.

\section{$5.1 \quad$ References}

Alvarado F., Brehm R., Kirsch L., Panvini A., (1996) "Retail pricing of reactive power service" EPRI Conference on Innovative Approaches to Electricity Pricing, La Jolla, CA, March 27-29.

Awerbuch S, Berger M,(2003) "Applying Portfolio Theory to EU Electricity Planning and Policy Making" - IEA/EET Working Paper.

Baldick, R. and William Hogan (2002), "Stability of Supply Function Equilibria: Implications for Daily Versus Hourly Bids In a Poolco Market," mimeo, Harvard Electricity Policy Group, February. 
Baldick, R. and William Hogan, (2001) "Capacity Constrained Supply Function Equilibrium Models of Electricity Markets: Stability, Non-Decreasing Constraints, and Function Space Iterations," mimeo, University of California Energy Institute POWER Working Paper PWP-089 December 2001 (Revised August 2002).

Bergen, A.R. (2000). "Power System Analysis", Prentice Hall, Englewood Cliffs, New Jersey, Chapters 5-6.

Berry C, Hobbs B, Meroney S, O'Neil R, Stewart W, "Understanding how market power can arise in network competition: a game theoretic approach" Utilities Policy 8 (1999) 139158.

Borenstein, Severin, James Bushnell, and Steven Stoft, (2000) "The Competitive Aspects of Transmission Capacity in a Deregulated Electricity Industry," RAND Journal of Economics 31(2) Summer, 294-325

Cardell, Judith B (1997), "Market Power and Strategic Interaction in Electricity Networks," Resource and Energy Economics 19(1-2) March, 109-37.

Denton (2003) "Managing Market Risk in Energy" - IEEE Transactions on Power Systems, August 2003.

Federal Energy Regulatory Commission (FERC) (2002) Notice of Proposed Rulemaking, "Remedying Undue Discrimination through Open Access Transmission Service and Standard Market Design," Docket No. RM01-12-000, July 31, 2002.

Gil J,(1999) "Reactive Power Pricing: A Conceptual Framework for Remuneration and Charging Procedures" IEEE Transactions on Power Systems, Vol. 15, Page(s): 483-489

GE final report "Singular Perturbations, Coherency and Aggregation of Dynamic Systems," pp.642, July 1981.

Green, Richard and David M. Newbery, (1992) "Competition in the British Electricity Spot Market," Journal of Political Economy, 100(5) October, 929-953.

Grossman S, Stiglitz J, (1980) “ On the Impossiblity of Informationally Efficient Markets. ” - 
American Economic Review, n 70, pp. 393-408

Hao S. (2003) "A Reactive Power Management Proposal for Transmission Operators" IEEE Transactions on Power Systems, Vol. 18, NO. 4. November.

Hao S., Papalexopoulos A, (1997) "Reactive Power pricing and management", IEEE Transactions on Power Systems, Vol. 12, Feb. 23-29

Hogan W. (1993) "Markets in Real Electric Networks Require Reactive Prices" The Energy Journal 14(3):211-242

Joskow Paul, and Jean Tirole, (2000), "Transmission rights and market power on electric power networks", RAND Journal of Economics 31(3) Autumn, 450-487

Joskow P (2003) "The Difficult Transition to Competitive Electricity Markets in the U.S." Cambridge Working Papers in Economics, July 2003.

Kahn E., and Baldick, R. (1994) "Reactive Power is a Cheap Constraint" The Energy Journal 15(4):191-201

Kirby B, (1977) "Ancillary Service Details: Voltage Control" - The National Regulatory Research Institute Columbus, Ohio. p.14

Klemperer, Paul, and Margaret A. Meyer, (1989) "Supply Function Equilibria in Oligopoly Under Uncertainty," Econometrica 57(6) November, 1243-1277.

Markowitz, H. (1952), "Portfolio Selection" - Journal of Finance 7, pp. 77-91

C. Murillo-Sanchez, (2001) R. Zimmerman, R. Thomas "Kirchhoff vs. Competitive Electricity Markets: A Few Examples" IEEE Power Engineering Society Winter Meeting 2001. Vol. 3, pp. $1256-1261$.

NERC (2004), "Planning Standards, North American Electric Reliability Council" //www.nerc.com [Online]

PJM (2004) web-site: www.pjm.com 
Reason J (1989). "Reactive-Power Compensation Avoids New Line Construction" Electrical World, October, p.35

Singh H., Papalexopoulos A. (1999) "Competitive Procurement of Ancillary Services by an Independent System Operator" IEEE Transactions on Power Systems, Vol 14, No. 2 May, 498504

Stoft, Steven (2002): Power System Economics: Designing Markets for Electricity. NY: WileyIEEE Press.

US. Department of Energy (2003) "Statement of by Kyle McSlarrow, Deputy Secretary of Energy, Before the House Committee on Energy and Commerce" Congressional Testimony, March 2003.

Weber J, (1998) “A Simulation Based Approach to Pricing Reactive Power" Hawai International Conference on System Sciences

Willems Bert (2002) "Modelling Cournot Competition in an Electricity Market with Transmission Constraints," The Energy Journal, 23(3),95-125.

Wilson Robert (2002), "Architecture of Power Markets," Econometrica, 70(4) July, 1299-1340.

Wolfram Catherine, (1998) "Strategic Bidding in a Multiunit Auction: An Empirical Analysis of Bids to Supply Electricity in England and Wales," RAND Journal of Economics 29(4), Winter, 703-725.

$\mathrm{Yu}$ (2003) "A spacial mean-variance MIP model for energy market risk analysis" - Energy Economics 25, pp. 255-268.

\subsection{Appendices}

\section{Appendix 2-A}

Existence and Uniqueness of Nash Equilibrium 
The solution to the SO's bidded cost-minimization problem can be represented by the system

$$
\frac{\partial B_{i}\left(a_{i}\left(x_{i}\right), x_{i}\right)}{\partial a_{i}\left(x_{i}\right)}\left[\frac{1}{\partial x_{i}(\cdot) / \partial a_{i}}\right]+\frac{\partial B_{i}\left(a_{i}\left(x_{i}\right), x_{i}\right)}{\partial x_{i}}=\lambda \quad i=1,2 \ldots n
$$

which represents $n$ independent non-linear first order differential equations. We assume that the bid is a monotonic function of the bid parameter, i.e.,

$$
\frac{\partial B_{i}(\cdot)}{\partial a_{i}} \neq 0
$$

for the region under consideration, $\left(\underline{a}_{i} \leq a_{i} \leq \bar{a}_{i} ; \underline{x}_{i} \leq x_{i} \leq \bar{x}_{i}\right)$. We can, without loss of generality, rewrite equation (5) in the form:

$$
\frac{\partial a_{i}\left(x_{i}\right)}{\partial x_{i}}=a_{i}^{\prime}=g\left(a_{i}, x_{i}\right) \quad i=1,2 \ldots N
$$

where

$$
g\left(a_{i}, x_{i}\right) \equiv \frac{\lambda-\frac{\partial B_{i}\left(a_{i}\left(x_{i}\right), x_{i}\right)}{\partial x_{i}}}{\frac{\partial B_{i}\left(a_{i}\left(x_{i}\right), x_{i}\right)}{\partial a_{i}\left(x_{i}\right)}}
$$

Assuming that all functions and their partial derivatives are continuous in the rectangle $\left(\underline{a}_{i} \leq a_{i} \leq\right.$ $\left.\bar{a}_{i} ; \underline{x}_{i} \leq x_{i} \leq \bar{x}_{i}\right)$, there exists a unique solution $a_{i}=\phi\left(x_{i}\right)$ given the initial value $a_{i}\left(x_{i_{0}}\right)=a_{i_{0}}$. (See Boyce, 1996, p.41).

Assuming that vector $\left(\underline{a}_{i} ; \underline{x}_{i}\right) \geq 0 \forall i$ there exists a positive vector of bids $\left(a_{1}, a_{2}, \ldots a_{N}\right) \geq 0$ and a positive production vector $\left(x_{1}, x_{2}, \ldots x_{N}\right) \geq 0$ that solves the SO's bidded-cost minimization problem, in equation (2). Solution of (2) implies equality of marginal bidded costs across generators, which, by solution of (1), is consistent with individual generators cost-minimization.

\section{EFFICIENCY PROOF OF BUNDLED LMPS}




\section{SO's cost minimization problem}

$$
\begin{aligned}
\min _{\left\{P_{1}, \ldots P_{n}\right\}} & \sum_{i=1}^{n} C_{i}\left(P_{i}, Q_{i}\left(P_{i}\right)\right) \\
\text { s.t. } & \sum_{i=1}^{n} P_{i}-P^{\operatorname{loss}}\left(P_{2}, \ldots P_{n}, Q_{2}\left(P_{2}\right), \ldots Q_{n}\left(P_{n}\right)\right)=P_{D} \\
& \sum_{i=1}^{n} Q_{i}\left(P_{i}\right)-Q^{\operatorname{loss}}\left(P_{2}, \ldots P_{n}, Q_{2}\left(P_{2}\right), \ldots Q_{n}\left(P_{n}\right)\right)=Q_{D}
\end{aligned}
$$

(Voltage, transmission, capacity etc. constraints)

$$
\begin{gathered}
\mathrm{E}=\sum_{i=1}^{n} C_{i}\left(P_{i}, Q_{i}\right)+\lambda\left(P_{D}-\sum_{i=1}^{n} P_{i}+P^{\operatorname{loss}}\left(P_{2}, \ldots P_{n}, Q_{2}\left(P_{2}\right), \ldots Q_{n}\left(P_{n}\right)\right)\right)+ \\
+\mu\left(Q_{D}-\sum_{i=1}^{n} Q_{i}\left(P_{i}\right)+Q^{\operatorname{loss}}\left(P_{2}, \ldots P_{n}, Q_{2}\left(P_{2}\right), \ldots Q_{n}\left(P_{n}\right)\right)\right)
\end{gathered}
$$

F.O.C.

$$
\begin{aligned}
\frac{\partial \mathrm{E}}{\partial P_{1}} \equiv \frac{\partial C_{1}(\cdot)}{\partial P_{1}}+\frac{\partial C_{1}(\cdot)}{\partial Q_{1}} \frac{\partial Q_{1}}{\partial P_{1}} & =\lambda+\mu \frac{\partial Q_{1}}{\partial P_{1}} \\
\frac{\partial \mathrm{E}}{\partial P_{i}} \equiv \frac{\partial C_{i}(\cdot)}{\partial P_{i}}+\frac{\partial C_{i}(\cdot)}{\partial Q_{i}} \frac{\partial Q_{i}}{\partial P_{i}} & =\lambda\left(1-\frac{\partial P^{\operatorname{loss}}(\cdot)}{\partial P_{i}}-\frac{\partial P^{\operatorname{loss}}(\cdot)}{\partial Q_{i}} \frac{\partial Q_{i}}{\partial P_{i}}\right)+ \\
& +\mu\left(\frac{\partial Q_{i}}{\partial P_{i}}-\frac{\partial P^{\operatorname{loss}}(\cdot)}{\partial P_{i}}-\frac{\partial P^{\operatorname{loss}}(\cdot)}{\partial Q_{i}} \frac{\partial Q_{i}}{\partial P_{i}}\right) \quad \forall i \geq 2
\end{aligned}
$$$$
L M P_{i} \equiv \frac{\partial C_{i}(\cdot)}{\partial P_{i}}+\frac{\partial C_{i}(\cdot)}{\partial Q_{i}} \frac{\partial Q_{i}}{\partial P_{i}}
$$$$
L M P_{i} \equiv \lambda\left(1-\frac{\partial P^{\operatorname{loss}}(\cdot)}{\partial P_{i}}-\frac{\partial P^{\operatorname{loss}}(\cdot)}{\partial Q_{i}}\right)+\mu\left(1-\frac{\partial Q^{\operatorname{loss}}(\cdot)}{\partial P_{i}}-\frac{\partial Q^{\operatorname{loss}}(\cdot)}{\partial Q_{i}}\right) \quad \forall i \geq 2
$$$$
\frac{L M P_{i}}{L M P_{1}}=\frac{\lambda\left(1-\frac{\partial P^{\operatorname{loss}}(\cdot)}{\partial P_{i}}-\frac{\partial P^{\text {loss }}(\cdot)}{\partial Q_{i}} \frac{\partial Q_{i}}{\partial P_{i}}\right)+\mu\left(\frac{\partial Q_{i}}{\partial P_{i}}-\frac{\partial P^{\operatorname{loss}}(\cdot)}{\partial P_{i}}-\frac{\partial P^{\text {loss }}(\cdot)}{\partial Q_{i}} \frac{\partial Q_{i}}{\partial P_{i}}\right)}{\lambda+\mu \frac{\partial Q_{1}}{\partial P_{1}}}
$$

where

$\lambda=\frac{C_{1}(\cdot)}{\partial P_{1}}$ marginal cost of real power only at the swing bus generator;

$\mu=\frac{C_{1}(\cdot)}{\partial Q_{1}}$ cost of reactive power for given level of real power at the swing bus generator.

When reactive power is free we get standard textbook result (see Bergen(2000)) 
$M R S=\frac{L M P_{i}}{L M P_{1}}=\frac{\frac{\partial C_{i}\left(P_{i}, Q_{i}\right)}{\partial P_{i}}}{\frac{\partial C_{1}\left(P_{1}, Q_{1}\right)}{\partial P_{1}}}=1-\frac{\partial P^{\operatorname{loss}}(\cdot)}{\partial P_{i}}$

\section{Generator's Problem}

In the competitive market each generator is a profit maximizer.

Generators profit

$$
\pi\left(P_{i}\right)=\mathrm{LMP}_{i} \times P_{i}-C_{i}\left(P_{i}, Q_{i}\left(P_{i}\right)\right)
$$

Profit maximizing condition

$$
\operatorname{LMP}_{i}=\frac{\partial C_{i}(\cdot)}{\partial P_{i}}+\frac{\partial C_{i}(\cdot)}{\partial Q_{i}} \frac{\partial Q_{i}}{\partial P_{i}}
$$

These LMPs solve overall cost minimization problem above and hence are efficient. 


\section{Appendix 3-C}

6-generators, 30 bus IEEE test power network.

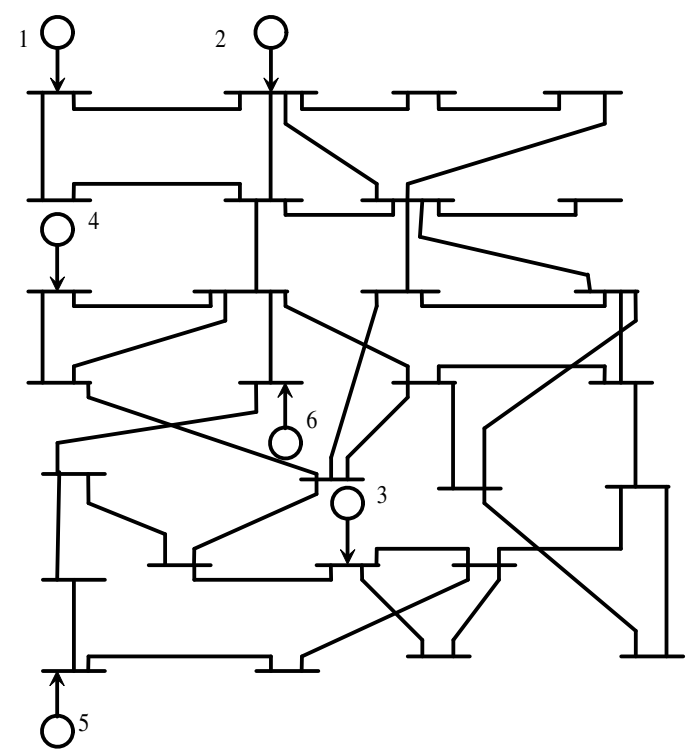

Figure 5.1: Economics of Competitive Prices for the Bundle of Real and Reactive Power 